\title{
Estimation of the Heat and Water Budgets of the Persian (Arabian) Gulf Using a Regional Climate Model ${ }^{*,+}$
}

\author{
Pengfei Xue \\ Great Lakes Research Center, Department of Civil and Environmental Engineering, Michigan Technological University, \\ Houghton, Michigan \\ ELFATIH A. B. ELTAHIR \\ Department of Civil and Environmental Engineering, Massachusetts Institute of Technology, Cambridge, Massachusetts
}

(Manuscript received 9 March 2014, in final form 9 January 2015)

\begin{abstract}
Because of the scarcity of observational data, existing estimates of the heat and water budgets of the Persian Gulf are rather uncertain. This uncertainty leaves open the fundamental question of whether this water body is a net heat source or a net heat sink to the atmosphere. Previous regional modeling studies either used specified surface fluxes to simulate the hydrodynamics of the Gulf or prescribed SST in simulating the regional atmospheric climate; neither of these two approaches is suitable for addressing the above question or for projecting the future climate in this region. For the first time, a high-resolution, two-way, coupled Gulf-atmosphere regional model (GARM) is developed, forced by solar radiation and constrained by observed lateral boundary conditions, suited for the study of current and future climates of the Persian Gulf. Here, this study demonstrates the unique capability of this model in consistently predicting surface heat and water fluxes and lateral heat and water exchanges with the Arabian Sea, as well as the variability of water temperature and water mass. Although these variables are strongly coupled, only SST has been directly and sufficiently observed. The coupled model succeeds in simulating the water and heat budgets of the Persian Gulf without any artificial flux adjustment, as demonstrated in the close agreement of model simulation with satellite and in situ observations.

The coupled regional climate model simulates a net surface heat flux of $+3 \mathrm{~W} \mathrm{~m}^{-2}$, suggesting a small net heat flux from the atmosphere into the Persian Gulf. The annual evaporation from the Persian Gulf is $1.84 \mathrm{~m} \mathrm{yr}^{-1}$, and the annual influx and outflux of water through the Strait of Hormuz between the Persian Gulf and Arabian Sea are equivalent to Persian Gulf-averaged precipitation and evaporation rates of 33.7 and $32.1 \mathrm{~m} \mathrm{yr}^{-1}$, with a net influx of water equivalent to a Persian Gulf-averaged precipitation rate of $1.6 \mathrm{~m} \mathrm{yr}^{-1}$. The average depth of the Persian Gulf water is $\sim 38 \mathrm{~m}$. Hence, it suggests that the mean residency time scale for the entire Persian Gulf is $\sim 14$ months.
\end{abstract}

\section{Introduction}

The Persian (Arabian) Gulf (hereafter referred to as the Gulf) is a semienclosed shallow sea between Iran (Persia) and the Arabian Peninsula, connected with the

\footnotetext{
* Supplemental information related to this paper is available at the Journals Online website: http://dx.doi.org/10.1175/JCLI-D-14-00189.s1.

${ }^{+}$Great Lakes Research Center at Michigan Technological University Contribution Number 19 .
}

Corresponding author address: Dr. Pengfei Xue, Michigan Technological University, 1400 Townsend Dr., Building GLRC-317, Houghton, MI 49931.

E-mail: pexue@mtu.edu
Gulf of Oman and the Indian Ocean through the Strait of Hormuz (hereafter referred to as the Strait). From the Strait, the Gulf stretches northwest for about $1000 \mathrm{~km}$ to Shatt al Arab (Arvand Roud) with a width that varies from a maximum of $\sim 340 \mathrm{~km}$ to a minimum of $\sim 55 \mathrm{~km}$ at the Strait. The water depth in the Gulf ranges from a few meters near the coast to more than $100 \mathrm{~m}$ at the Strait, with a mean depth of $\sim 38 \mathrm{~m}$ (Fig. 1a). The primary circulation pattern is a cyclonic gyre with the inflow of Arabian Sea waters coming mainly through the northern part of the Strait and forming a cyclonic circulation gyre returning to the southern Gulf (Reynolds 1993). The northern Gulf can maintain a smaller cyclonic circulation while southward coastal currents exist between the head of the Gulf and Qatar and extend to 

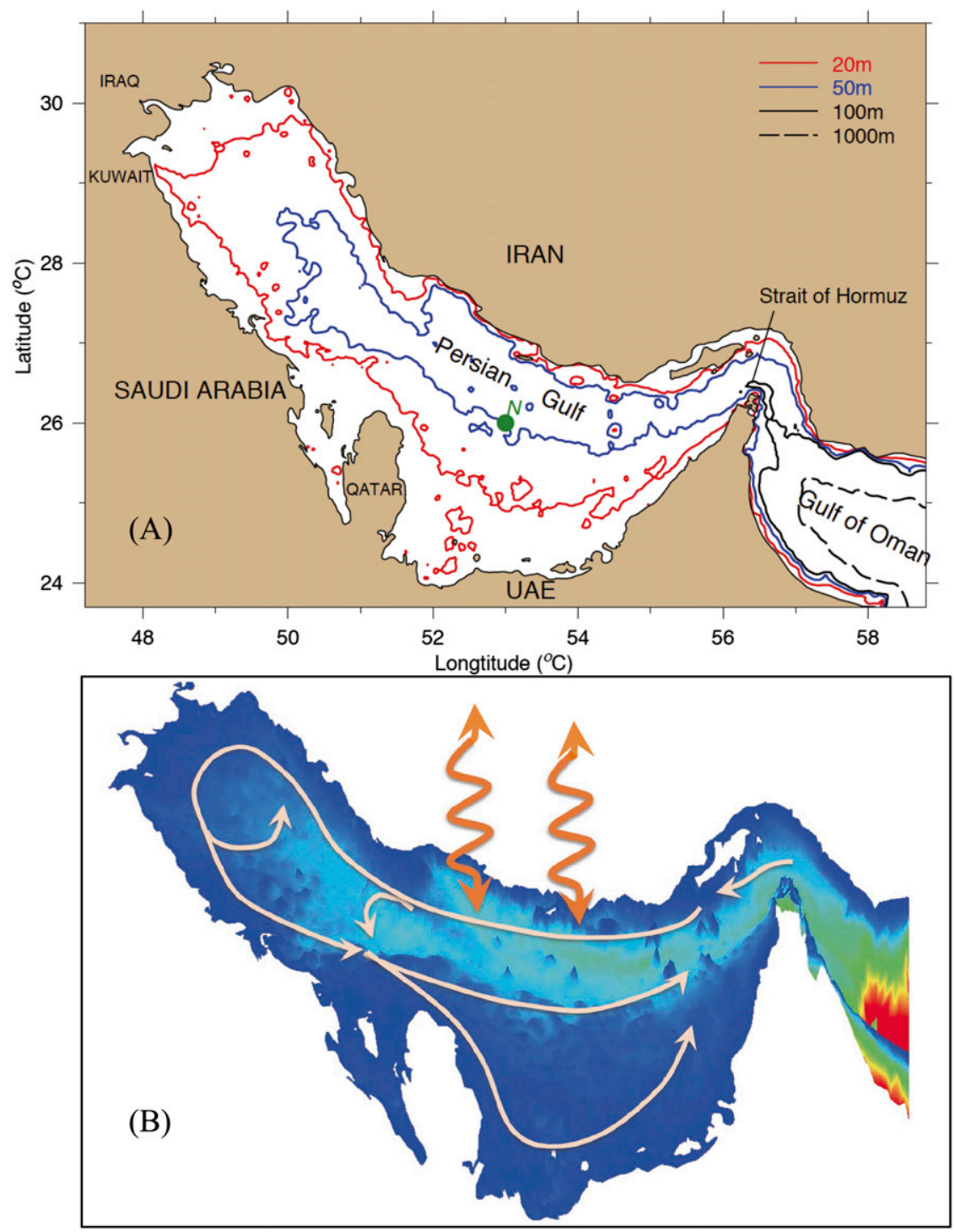

FIG. 1. (top) The geographic features and (bottom) the schematic of the circulation of the Gulf shown with grey-brown arrows. Air-sea interactions are indicated by red-brown arrows. The color of the Gulf indicates the water depth (warmer color for deeper water).

the east of Qatar and north of United Arab Emirates (UAE) with an outflow through the southern part of the Strait (Fig. 1b).

Surrounded by natural geologic formations that contain two-thirds of the world's estimated proven oil reserves and one-third of the world's estimated proven natural gas reserves, the Gulf is located in an important economic and political region, representing the most important route for global transport of oil and gas. The countries surrounding the Gulf are experiencing some of the highest rates of economic and population growths, resulting in an increasing level of environmental stress (Sheppard et al. 2010). More than any other water body, the Gulf water is desalinated at an increasing rate to provide the main source of water supply for most of the population in the surrounding cities and countries. The surface water temperature in the Gulf has also exhibited a significant increase in the recent two decades (Shirvani et al. 2014). Concerns are rising about sustainability of these trends into the future, while climate change and its impacts complicate this situation even further (Hamza and Munawar 2009; Sale et al. 2011).

Because of the limited observational data, previous estimates of heat and water budgets are highly uncertain. This is a major hurdle in understanding the current climate of the Gulf system and in projecting its future trends. The annual-mean value of net 
TABLE 1. Basin-averaged annual-mean heat fluxes and evaporation rate of the Gulf, estimated by previous studies. N/A means not applicable.

\begin{tabular}{lccc}
\hline \multicolumn{1}{c}{ References } & $\begin{array}{c}\mathrm{Net} \\
\left(\mathrm{W} \mathrm{m}^{-2}\right)\end{array}$ & $\begin{array}{c}\text { Latent } \\
\left(\mathrm{W} \mathrm{m}^{-2}\right)\end{array}$ & $\begin{array}{c}\text { Evaporation } \\
\left(\mathrm{m} \mathrm{yr}^{-1}\right)\end{array}$ \\
\hline Privett (1959) & N/A & 114.16 & 1.44 \\
Hastenrath et al. (1979) & 45 & 110.00 & 1.39 \\
Meshal and Hassan (1986) & N/A & 160.13 & 2.02 \\
Ahmad and Sultan (1991) & -21 & 168.00 & 2.12 \\
Prasad et al. (2001) & 66 & N/A & N/A \\
& 51 & N/A & N/A \\
Johns et al. (2003) & 63 & N/A & N/A \\
& $-7 \pm 4$ & 145.07 & 1.83 \\
Abualnaja (2009) & 4 & 122.00 & 1.58 \\
& 8 & N/A & N/A \\
\hline
\end{tabular}

surface heat flux estimated by various studies ranges from $+66 \mathrm{~W} \mathrm{~m}^{-2}$ flux into the Gulf to $-21 \mathrm{~W} \mathrm{~m}^{-2}$ loss from the Gulf (Ahmad and Sultan 1991; Hastenrath et al. 1979; Johns et al. 2003; Prasad et al. 2001; Abualnaja 2009). [The net surface heat flux is the balance between incoming solar radiation, reflected solar radiation, downward longwave radiation, upward longwave radiation, latent heat flux (evaporation), and sensible heat flux.] This uncertainty leaves open the fundamental question of whether this water body is a net heat source or a net heat sink to the atmosphere. Our knowledge of the rate of evaporation, which is a significant component of both the heat budget and water budget, has also been quite uncertain, with estimates ranging from 1.4 to $2.1 \mathrm{~m} \mathrm{yr}^{-1}$ (Privett 1959; Meshal and Hassan 1986; Hastenrath et al. 1979; Ahmad and Sultan 1991; Johns et al. 2003). A summary of the previous estimates of the surface heat flux and evaporation rate is presented in Table 1.

To characterize the heat and water budgets of the Gulf, we need to constrain consistent estimates of evaporation, net surface heat flux, and lateral heat flux. The dominance of the fluxes in regulating SST is due to the shallow nature and semienclosed basin of the Gulf. Given the shallow nature of this water body (average depth of $38 \mathrm{~m}$ ), the SST is as much a reflection of these surface fluxes as a forcing of the fluxes. In water bodies that are as shallow as the Gulf, the water mixed layer and atmospheric mixed layer are of comparable heat content, and the two components of a coupled system evolve simultaneously with significant two-way interactions. Previous regional modeling studies either used specified surface fluxes to simulate the hydrodynamics of the Gulf (Chao et al. 1992; Kämpf and Sadrinasab 2006; Sadrinasab and Kämpf 2004; Thoppil and Hogan 2010; Yao and Johns 2010a; Yao and Johns 2010b; Hassanzadeh et al. 2011; Hassanzadeh et al.
2012) or prescribed SST in simulating the regional atmospheric climate (Evans et al. 2004; Marcella and Eltahir 2008, 2012). Because of the shallow nature of this water body, neither of these two approaches is suitable for addressing the above questions or projecting future climate in this region. The most suitable approach is to consistently estimate evaporation and all other heat fluxes through the use of a laterally constrained and vertically coupled Gulfatmosphere model.

The remaining part of this paper is organized as follows: Section 2 describes the data used in this study, the coupled ocean-atmosphere model, and the design of experiments. Section 3 presents the results of the coupled simulation in comparison to uncoupled simulations and observational data. In section 4, the heat and water budgets are examined at both seasonal and annual time scales. The discussion is presented in section 5, and brief conclusions are summarized in section 6 .

\section{Methods}

\section{a. Model}

To the best of our knowledge, this is the first coupled ocean-atmosphere model developed for the Gulf, known as the Gulf-atmosphere regional model (GARM), in which we synchronously coupled a regional ocean model to a regional atmospheric climate model. The Gulf model was developed using unstructured grid Finite Volume Coastal Ocean Model (FVCOM) (Chen et al. 2003). With the merit of an unstructured grid for ideal geometrical fitting (Chen et al. 2006; Tian and Chen 2006; Xue et al. 2009), FVCOM has gained its popularity in research and applications to estuaries and coastal oceans (Weisberg and Zheng 2006; Chen et al. 2008; Cowles et al. 2008; Zhao et al. 2010; Xue et al. 2011; Beardsley et al. 2013; Chen et al. 2014). The horizontal resolution of the model grid varies from $\sim 3 \mathrm{~km}$ near the coast to $\sim 5 \mathrm{~km}$ in the offshore region of the Gulf and gradually decreases to $10-15 \mathrm{~km}$ close to the open boundary (Fig. 2). As the Gulf is a shallow-water system with a mean depth of $\sim 38 \mathrm{~m}$, the model is configured with 30 generalized sigma layers, in which 30 uniform sigma layers are configured to provide the vertical resolution of $<1 \mathrm{~m}$ for nearshore waters and $\sim(1-2) \mathrm{m}$ in most offshore regions of the Gulf. Climatological monthly mean fields of temperature (Locarnini 2010) and salinity (Antonov 2010) from the World Ocean Atlas 2009 (WOA09), which consists of $1^{\circ}$ objectively analyzed, climatological fields of in situ temperature and 


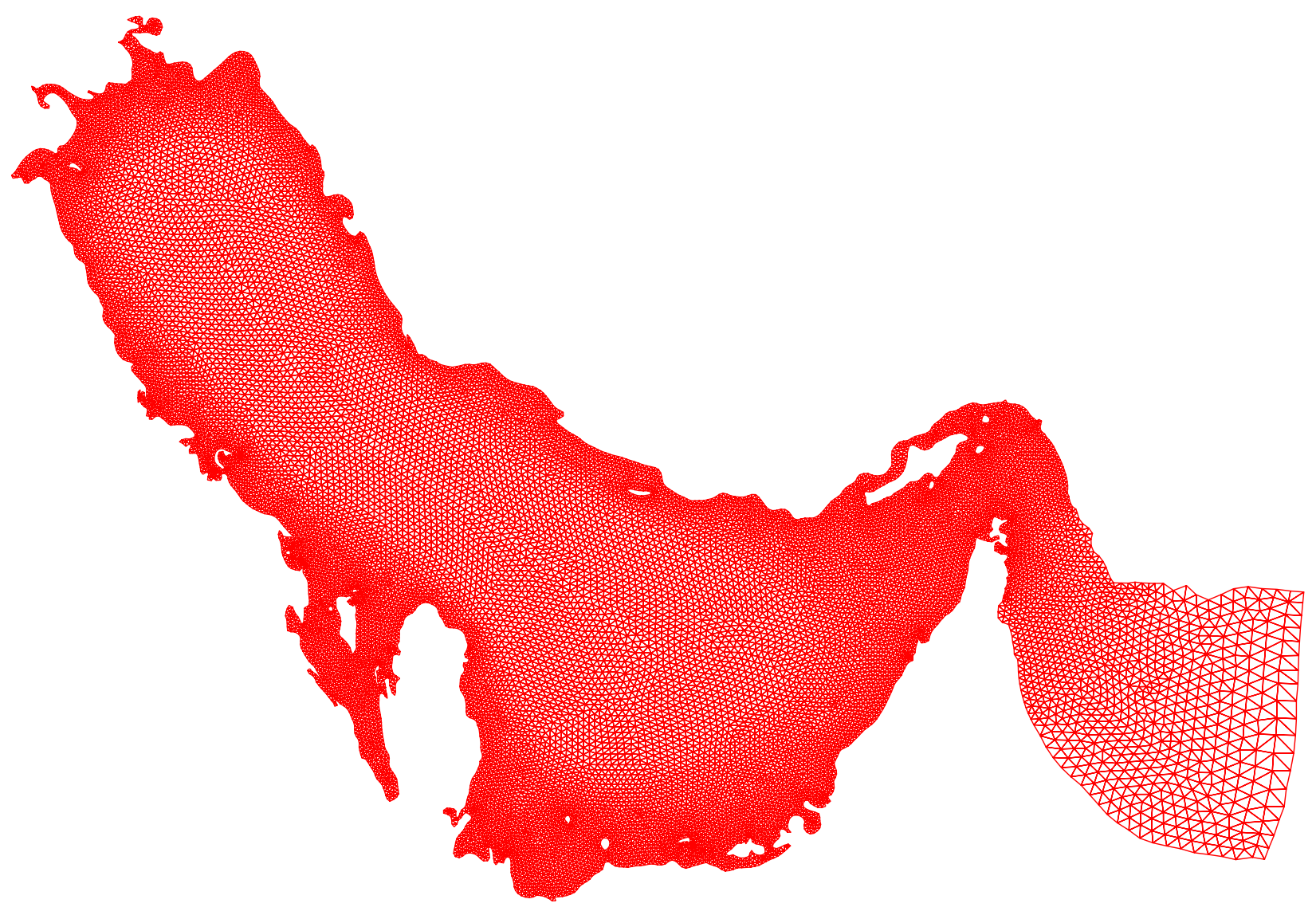

FIG. 2. The unstructured triangular mesh of the Gulf model.

salinity at standard depth levels for annual, seasonal, and monthly compositing periods for the World Ocean, are applied to the model open boundary. The mean flow velocity boundary condition is dynamically calculated in the model based on the wind and water temperature and salinity information to resolve the wind-driven and buoyancy-driven mean flow components. The major freshwater inflow from the Shatt al Arab (Arvand Roud) formed by the confluence of the Euphrates, Tigris, and Karun Rivers was specified based on the streamflow statistics for the Tigris River and Euphrates River basins (Saleh 2010). The climatological monthly mean of the river inflow is used with an annual-mean transport of $1576 \mathrm{~m}^{3} \mathrm{~s}^{-1}$ and highflow seasons between March and May (Table 3). The surface forcing (surface wind, precipitation, evaporation, shortwave and longwave radiation, and latent and sensible heat fluxes) is provided by the atmospheric model at 3-h intervals. The Mellor-Yamada level-2.5 turbulence closure (Mellor and Yamada 1982) scheme is used for vertical mixing parameterization, and the horizontal diffusion is parameterized using Smagorinsky formulation (Smagorinsky 1963).
The external and internal mode time steps are 6.0 and $60.0 \mathrm{~s}$, respectively.

The atmospheric model, the Massachusetts Institute of Technology (MIT) regional climate model (MRCM), is an advanced version of the Regional Climate Model, version 3 (RegCM3) (Giorgi and Mearns 1999; Pal et al. 2007), with a focus on improving the skill of RegCM3 in simulating climate over different regions through the incorporation of new physical schemes or modification of original schemes, including coupling of the Integrated Biosphere Simulator (IBIS) land surface scheme (Winter et al. 2009), new convective cloud scheme (Gianotti and Eltahir 2014a), new convective rainfall autoconversion scheme (Gianotti and Eltahir 2014b), modified boundary layer height and boundary layer cloud scheme (Gianotti 2013), and new surface albedo assignment (Marcella and Eltahir 2012) and irrigation scheme (Marcella and Eltahir 2014). Ocean surface fluxes in MRCM are handled by Zeng's bulk aerodynamic ocean flux parameterization scheme (Zeng et al.1998) with SST fields provided by the ocean model in the coupled simulation. Owing to the different spatial scales of atmospheric and Gulf circulation, the 
MRCM is configured to cover a larger domain between $12^{\circ}$ and $40.5^{\circ} \mathrm{N}$ and $29^{\circ}$ and $61^{\circ} \mathrm{E}$ with $30-\mathrm{km}$ resolution in $120 \times 120$ grids.

Since our long-term research goal is to project the impact of future climate on the Gulf and only global general circulation models may provide the atmospheric model boundary conditions for the future climate, we chose datasets that describe the current climate (198190) as simulated by the ECHAM 5 /Max Planck Institute Ocean Model (MPIOM) climate model of the Max Planck Institute for Meteorology, which has now been updated and renamed the Max Planck Institute Earth System Model (MPI-ESM) in the phase 5 of the Coupled Model Intercomparison Project (CMIP5), to provide atmospheric boundary conditions to our regional model in this study. Considered one of the better global climate models, its skill has been documented in a special issue of the Journal of Climate (2006, Vol. 19, No. 16) devoted to climate models at the Max Planck Institute for Meteorology. The initial and boundary conditions were specified at 6-h intervals [in a sensitivity analysis, a second coupled simulation driven by ERA-40 reanalysis datasets has also been conducted and the results are quite similar to those using ECHAM5 (see section 5)]. The lateral boundary condition includes the surface pressure and wind components, air temperature, vertical velocity, relative humidity, and geopotential height at all vertical sigma levels.

While the atmosphere-only MRCM simulation uses prescribed SST (obtained from ECHAM5/MPIOM dataset) as the surface boundary condition, the SST information in the coupled model simulation is predicted by the Gulf-FVCOM model and provided to the atmospheric-MRCM model. The MRCM runs with a time step of $60 \mathrm{~s}$, and the radiation scheme and land surface scheme are run every $30 \mathrm{~min}$ and every $180 \mathrm{~s}$, respectively. The FVCOM and MRCM are coupled using the Ocean Atmosphere Sea Ice Soil coupler, version 3 (OASIS3), software in parallelized computation environment (Valcke 2013).

To assess the significance of two-way air-sea feedback processes in shaping the climate of the Gulf, uncoupled model experiments were also carried out. The atmosphere-only simulation with the MRCM, forced with SST from the ECHAM/MPIOM database, was conducted to estimate the atmospheric surface

\footnotetext{
${ }^{1}$ ECHAM is the global climate model, created by modifying the global forecast models developed by the European Centre for Medium-Range Weather Forecasts (ECMWF). The model was given its name as a combination of its origin (the EC being short for ECMWF) and the place of development of its parameterization package, Hamburg.
}

TABLE 2. Experimental design of coupled and uncoupled model simulations.

\begin{tabular}{lll}
\hline \hline \multicolumn{1}{c}{ Experiment design } & \multicolumn{1}{c}{ SST } & $\begin{array}{c}\text { Lateral boundary } \\
\text { (atmosphere/ocean) }\end{array}$ \\
\hline Coupled model (case 1) & Simulated & ECHAM5/WOA09 \\
Coupled model (case 2) & Simulated & ERA-40/WOA09 \\
Atmosphere-only model & Prescribed & ECHAM5/WOA09 \\
Ocean-only model & Simulated & N/A/WOA09 \\
\hline
\end{tabular}

forcing, which was then used to drive an ocean-only model (FVCOM) simulation. The design of the experiments performed in this study is summarized in Table 2.

\section{b. Data}

For the comparison of the SSTs from the coupled and ocean-only model simulations, we use two datasets for verification: NOAA optimum interpolation daily SST analysis $0.25^{\circ} \times 0.25^{\circ}$ resolution gridded data (Reynolds et al. 2007) (OISST only available from 1982) and Simple Ocean Data Assimilation (SODA 2.2.4) with $0.5^{\circ} \times 0.5^{\circ}$ resolution gridded data (Carton and Giese 2008), selected for the simulation years 1981-90.

\section{Model data comparison}

Figure 3 presents the Gulf-averaged $\mathrm{SST}^{2}$ simulated with the coupled and uncoupled ocean-only models for 1980s. Results of the coupled model simulation demonstrate a close agreement with the observed OISST and the SODA-assimilated product, successfully reproducing both an equilibrium mean state of $\sim 26^{\circ} \mathrm{C}$ and the large seasonal variability of $\sim 14.5^{\circ} \mathrm{C}$. In contrast, the SST of the uncoupled simulation shows a cold drift for the first $2 \mathrm{yr}$ and reaches a significantly colder equilibrium state (Fig. 3). The coupled model simulation also demonstrates significant skills in reproducing a general spatial pattern of the SST with larger variation in the northwest coast and smaller in the southeast near the Strait (Fig. 4). During wintertime, the averaged SST is between $16^{\circ}$ and $20^{\circ} \mathrm{C}$ with colder waters occupying the northwest of the Gulf and relatively warmer waters in the southeast of the Gulf. During summertime, the warm surface water of $\sim 31^{\circ} \mathrm{C}$ occupies the entire Gulf with weaker spatial gradients of SST between $30^{\circ}$ and

\footnotetext{
${ }^{2}$ To make the comparisons consistent, SODA and OISST datasets are first interpolated into FVCOM model grids and then the Gulf-averaged SST are calculated as grid size-weighted average based on the area of individual control volume $(\mathrm{CV})$ also called the tracer control element (TCE) associated with each FVCOM model grid.
} 


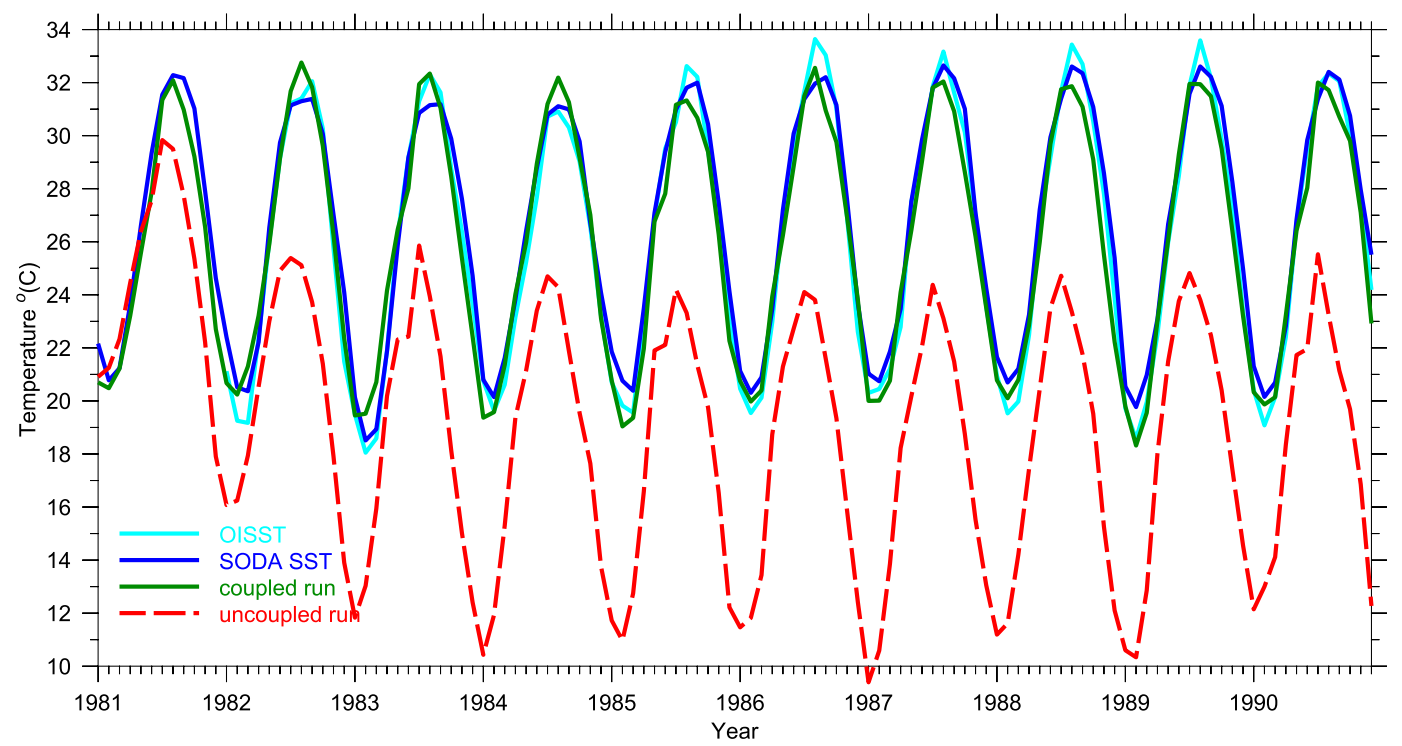

FIG. 3. The time evolution of the Gulf-averaged SST using the coupled (green) and uncoupled (red) ocean-only model compared with two independent SST datasets: daily OISST (aquamarine) and SODA (blue) surface layer (5 m) temperature for the years 1981-90.

$32^{\circ} \mathrm{C}$. The uncoupled model simulation, on the other hand, shows a systematic cold bias over the entire basin in all seasons.

Consistent with the large difference in the simulated SSTs between the coupled and uncoupled (ocean only) model simulations, significant differences in the estimated surface heat fluxes are found between the coupled and uncoupled (atmosphere only) model simulations (Fig. 5, top panels). Estimated from the simulation with the atmosphere-only model, the net surface heat flux prescribed to force the uncoupled ocean model has a decadal-averaged mean value of $\sim-27 \mathrm{~W} \mathrm{~m}^{-2}$. This prescribed value indicates a net heat loss from the Gulf to the atmosphere, while the coupled modeling system estimates a net surface heat flux of $\sim+3 \mathrm{~W} \mathrm{~m}^{-2}$, suggesting a small net heat flux from the atmosphere into the Gulf. The $30 \mathrm{~W} \mathrm{~m}^{-2}$ difference is clearly responsible for the cold bias of the uncoupled simulation. Moreover, the net surface heat flux simulated by the uncoupled model also shows a phase shift of the seasonal cycle, resulting in an oscillation pattern when comparing the difference in the net surface heat flux simulated by the uncoupled and coupled model (Fig. 5, top-right panel); such a phase shift is also reflected in the SST simulations in Fig. 3.

A close examination of each component of the surface heat fluxes in the coupled and uncoupled simulations reveals that the largest difference in the surface heat budget comes from the latent heat flux, not surprisingly, because of the excessive evaporation in the Gulf (Fig. 5, middle and bottom panels). The atmosphere-only model overestimates the latent heat loss from the Gulf by $27 \mathrm{~W} \mathrm{~m}^{-2}$, which accounts for $\sim 90 \%$ of the total discrepancy between the net surface heat flux estimated by the atmosphere-only model and by the coupled model. The differences in other heat flux components estimated by atmosphere-only and coupled simulations are at least one order of magnitude smaller than the difference in latent heat flux and only account for $\sim 10 \%$ of the total difference in the surface heat budget. The atmosphereonly model and coupled model estimate annual-mean values of latent heat flux of 173 and $146 \mathrm{~W} \mathrm{~m}^{-2}$. Assuming the latent heat of vaporization $L_{e}=2.5 \times 10^{6} \mathrm{~J} \mathrm{~kg}^{-1}$, corresponding surface evaporation rates are 2.2 and $1.84 \mathrm{~m} \mathrm{yr}^{-1}$, respectively. The former is close to the upper end (Ahmad and Sultan 1991) of a wide range of estimates of evaporation by previous observation-based studies, while the latter is closer to the ensemble mean of these studies (Table 1; Privett 1959; Meshal and Hassan 1986; Hastenrath et al. 1979; Ahmad and Sultan 1991; Johns et al. 2003). In addition, observations at two individual sites (Bushehr and Bandar-Abbass) in Iran located near the northern coast of the Gulf are documented with long-term mean values of evaporation rates of 1.57 and $1.61 \mathrm{~m} \mathrm{yr}^{-1}$ (Sabziparvar et al. 2011; Sabziparvar et al. 2013) and reasonably agree with the Gulf-averaged estimates of the coupled simulation as well as local estimates from the closest model grids of 1.75 and $1.82 \mathrm{~m} \mathrm{yr}^{-1}$. A further analysis of the differences in the relative humidity and wind speed in the coupled and uncoupled simulations shows that the lower relative humidity and higher wind speed in the uncoupled simulation accounts for the 

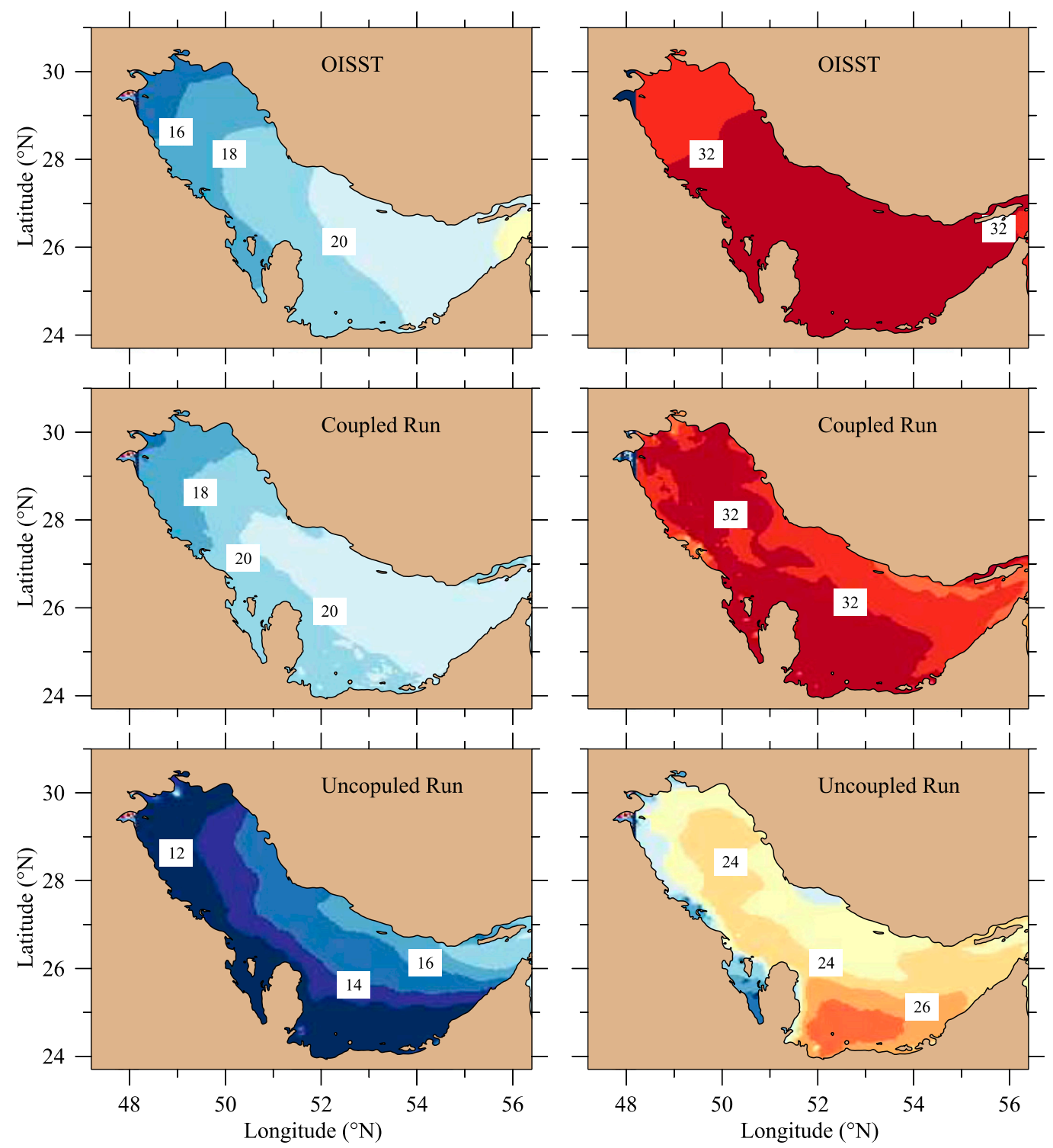

FIG. 4. Horizontal distributions of decadal-averaged SST in (left) February (coldest month) and (right) August (warmest month) from (top to bottom) OISST and the coupled and uncoupled model simulations. The numbers in the panels represent the temperature that corresponds with its color scale value.

overestimated heat loss (see Figs. S1 and S2 in the supplemental material, available online at http://dx.doi.org/ 10.1175/JCLI-D-14-00189.s1.).

As an evaporation-driven system, the freshwater loss through the surface evaporation plays an import role in the formation of the high-salinity water body in the Gulf. Therefore, the model performance in the simulation of salinity should be an additional evidence of the accuracy of the model. Figure 6 presents the comparison of sea surface salinity (SSS) estimated from the SODA dataset, the coupled model, and the uncoupled ocean model. Both model simulations and SODA data show a good agreement of the horizontal distribution of the SSS. Water with salinity between 40 and 41 occupies most of the Gulf region except near the Strait with highly saline water (salinity $>41$ ) existing in the southern Gulf. During the springtime with a large amount of freshwater from the Shatt al Arab (Arvand 

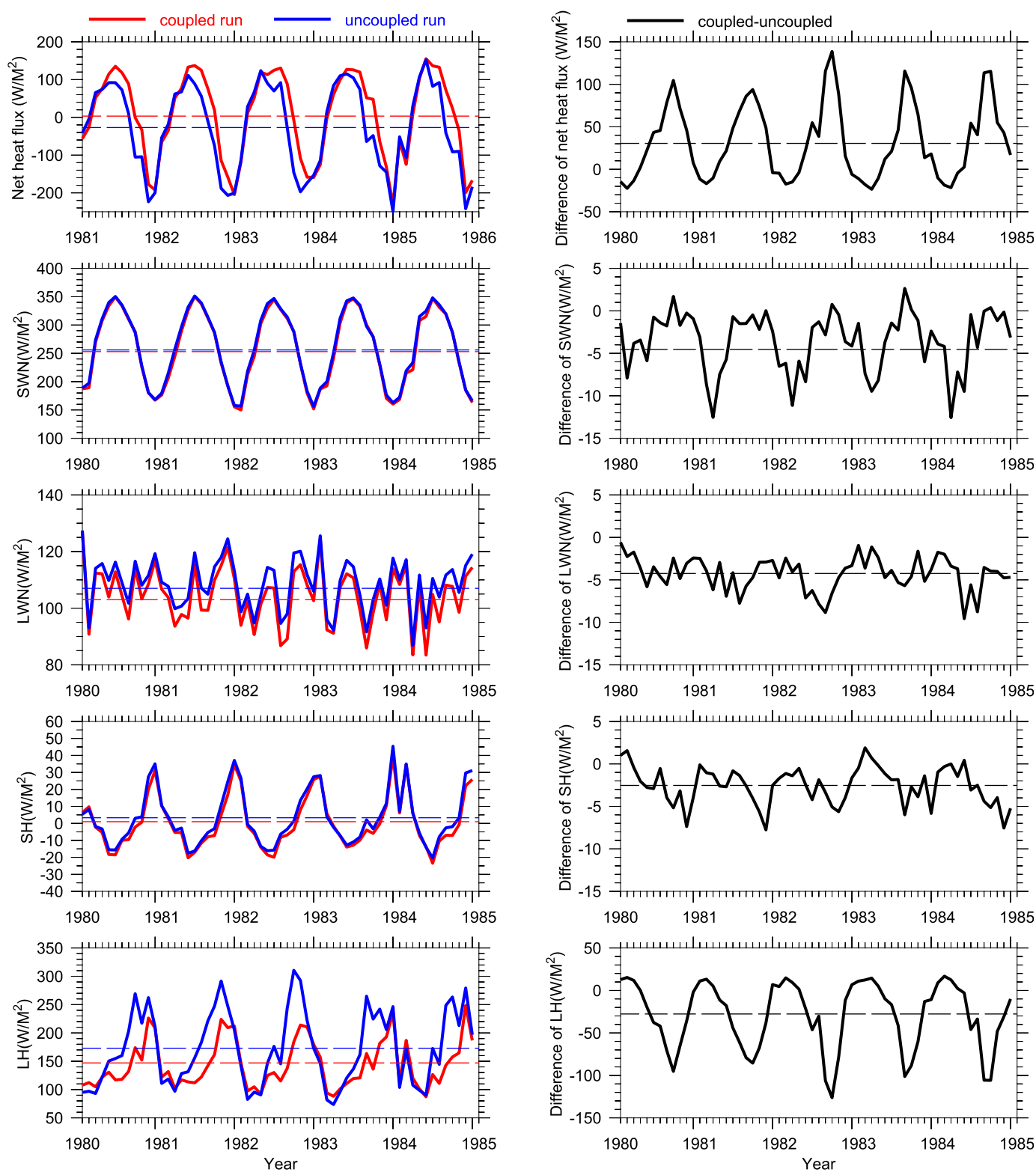

FIG. 5. The time series of the Gulf-averaged surface heat fluxes-(top to bottom) net heat flux, net shortwave radiation (SWN), net longwave radiation ( $\mathrm{LWN})$, sensible heat $(\mathrm{SH})$, and latent heat (LH) - estimated by the (left) coupled (red) and uncoupled (blue) atmosphere-only model and (right) their differences. For a clear view, only 5-yr time series are plotted here, while the analysis was conducted for the entire $10-\mathrm{yr}$ simulation.

Roud), the river plume extends southeastwards along the coast, which is reproduced in the model simulations while the freshwater discharge is not reflected in the SODA dataset. Both the models' results and SODA product suggest that the saltiest waters are confined near the coastal region around Qatar and UAE in all seasons, while relatively fresher waters from the Strait intrude along the northern coast of the Gulf. An interesting point is that the SSS simulated by the uncoupled ocean model is slightly lower than that simulated by the coupled simulation, yet the uncoupled atmospheric model simulates a higher evaporation rate (which is one of the surface forcing for the uncoupled ocean-only simulation) than the coupled simulation. The possible causes and implications are discussed in the section 5.

Another important factor in determining the water and heat budgets of the Gulf that needs to be assessed is the flow structure in the Strait, which has a critical 


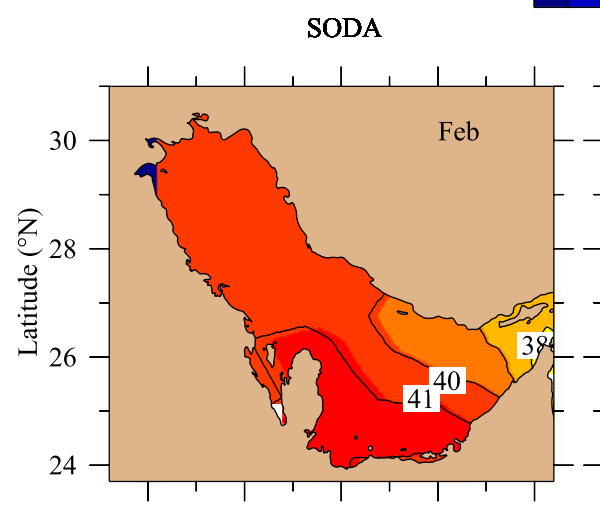

\section{Coupled Run Uncoupled Run}
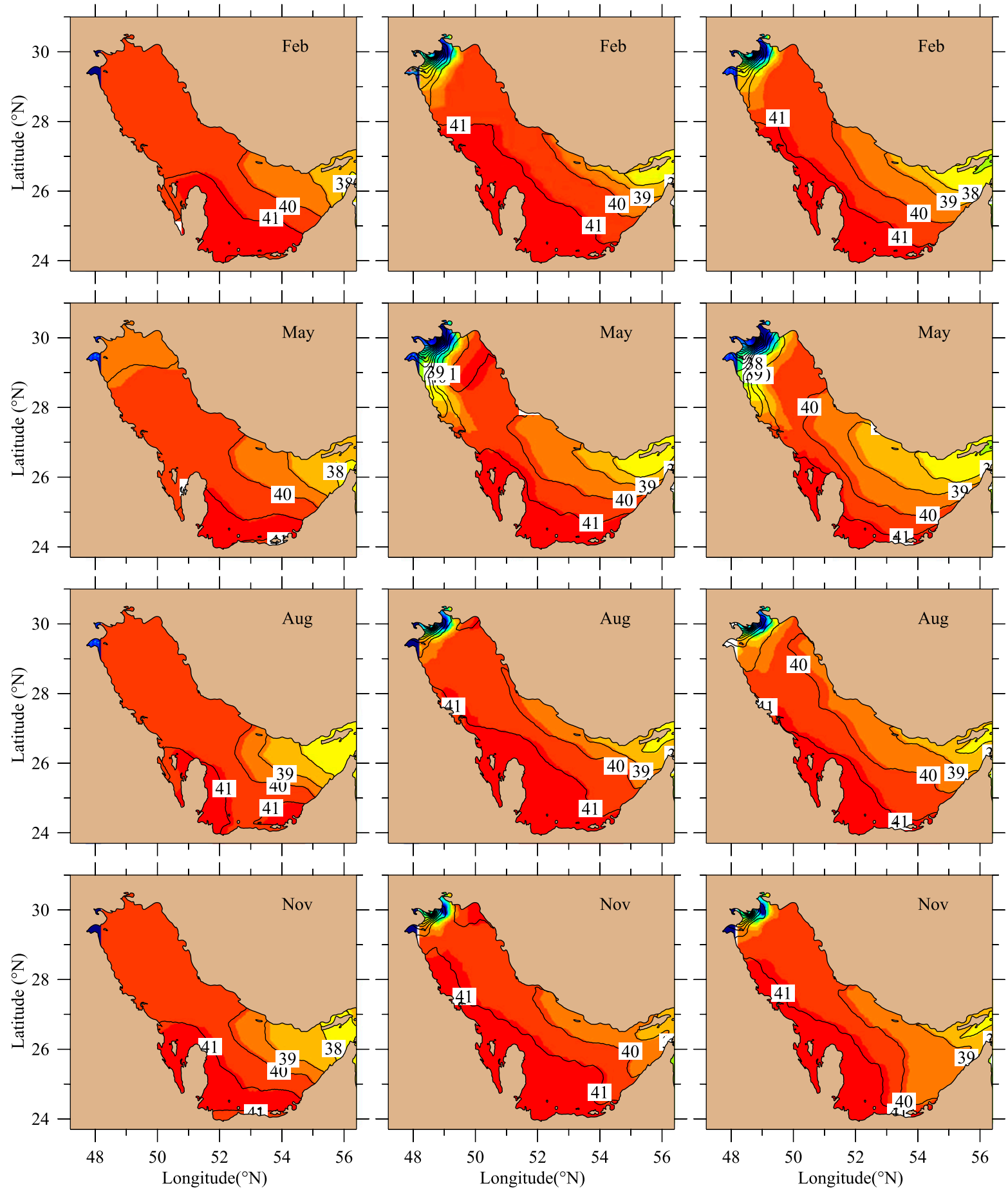

FIG. 6. Horizontal distributions of decadal-averaged surface layer salinity in (top to bottom) February, May, August, and November from (left to right) the SODA dataset and coupled and uncoupled model simulations. 

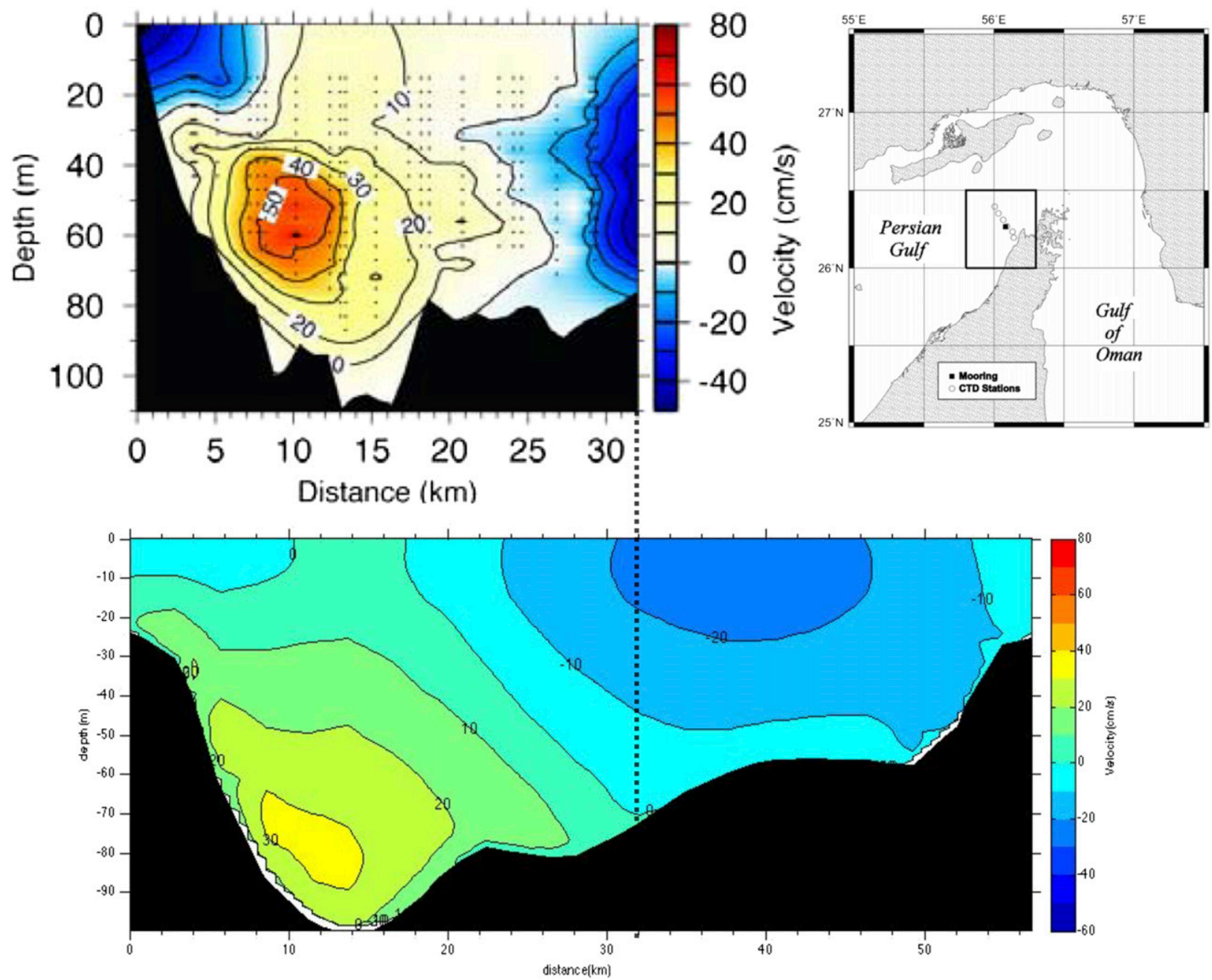

FIG. 7. (top left) Cross-section mean flow velocity and the (top right) location of the sampling transect (dot within outlined rectangle), observational data reproduced from the Johns et al. (2003) cruise sampling in March 1997. (bottom) The simulated climatological monthly cross-section velocity in March from the coupled simulation. The velocities in the panels are in $\mathrm{cm} \mathrm{s}^{-1}$.

impact on lateral transport of both water and heat through the Strait. As hydrographical samplings were hardly available in the Strait, we chose to make a comparison of simulated flow structure with one of the recently published observations near the Strait by Johns et al. (2003). We note here that the section covered by observations is from one of their cruises made in March 1997 across the southern half of the Strait, while our climate model simulation was performed for the 1980s. Yet, the model-simulated monthly climatology of inflow and outflow structures in March is still quite similar to the observations (Fig. 7). Both observational data and model simulation show a primary deep-water outflow at the southern side of the transect, $\sim 10 \mathrm{~km}$ away from the Oman coast; a primary inflow located in the northern side of the transect as well as very weak surface inflow near the Oman coast. [The observation clearly identified the edge of the inflow core but was not able to sample farther north. According to Johns et al. (2003), their research clearances were only available from Oman and therefore the northern half of the Strait in Iran's territorial waters could not be sampled.] It would not be accurate to make direct comparison between a cruise sampling and model-simulated climatological monthly mean flow, and hence we estimated the variability of the inflow and outflow in March using the climatological daily mean values from the model simulation, which have standard deviations of 0.15 and $0.1 \mathrm{~m} \mathrm{~s}^{-1}$ with maximum values of 0.65 and $0.5 \mathrm{~m} \mathrm{~s}^{-1}$, respectively. The large variability (the variability of instantaneous flow shall be even larger) implies that the differences between the simulated mean flow and observed instantaneous flow are in a reasonable range. More importantly, only one long-term velocity measurement 
(Johns et al. 2003) from the ADCP at the southern side of this transect at 80-m depth shows that the 15-day lowpass filtered mean flow ranges from 0.2 to $0.3 \mathrm{~m} \mathrm{~s}^{-1}$, which is in a very good agreement with the model-simulated, climatological, monthly mean velocity $\left(0.3 \mathrm{~m} \mathrm{~s}^{-1}\right)$ at the transect.

\section{Water and heat budgets}

\section{a. Formulation of water and heat balance}

The water balance in the Gulf is controlled by 1) lateral water exchange with the Arabian Sea through the Strait including inflow and outflow and 2) water fluxes in and out of the Gulf through rainfall, river flow, and evaporation. This balance is formulated as

$$
\frac{d \bar{V}}{d \bar{T}}=P-E+R+L_{\text {in }}-L_{\text {out }},
$$

where $d \bar{V}$ is the change in total water volume over time scale $d \bar{T}$. The terms $E, P, R, L_{\mathrm{in}}$, and $L_{\text {out }}$ are the water transports by evaporation and precipitation over the Gulf, the river flow, and the inflow and outflow through the Strait. While $R$ is specified, $E$ and $P$ are calculated by the atmospheric model, and $L_{\text {in }}$ and $L_{\text {out }}$ are calculated with the currents into and out of the Gulf through the Strait $\left(\mathbf{v}_{\text {in }}\right.$ and $\left.\mathbf{v}_{\text {out }}\right)$ in the ocean model.

The heat balance in the Gulf reflects 1) net surface heat flux, 2) lateral heat exchange with the Arabian Sea through the Strait, 3) heat transport associated with water fluxes in and out of the Gulf (rainfall, river flow, and evaporation), 4) solar radiation absorbed by the soil underlying shallow-water regions, and 5) total heat change in the water body in the Gulf. This total heat change is the key factor controlling the climate of the Gulf and surrounding coastal regions. The coupled model is able to provide a significant insight into the relative roles of surface heat fluxes and lateral heat fluxes in controlling the current and future climate of this system.

The heat balance is given by

$$
\begin{aligned}
\frac{d \bar{Q}}{d \bar{T}}= & \mathrm{NR}-\mathrm{LH}-\mathrm{SH}-\mathrm{LTH}_{\mathrm{out}}+\mathrm{LTH}_{\mathrm{in}} \\
& -\mathrm{WH}_{E-P}+\mathrm{WH}_{R}-\mathrm{GH},
\end{aligned}
$$

where $d \bar{Q}$ is the total heat content change in water body over the time scale $d \bar{T}, N R$ is the net radiation flux over the Gulf, $\mathrm{LH}$ and $\mathrm{SH}$ are the latent and sensible heat fluxes, and $\mathrm{LTH}_{\text {out }}$ and $\mathrm{LTH}_{\text {in }}$ are the heat transport through the Strait. The term $\mathrm{WH}_{R}$ is the heat transport through the river flow; $\mathrm{WH}_{E-P}$ represents the heat transport carried by the water volume that leaves the basin through its surface via the evaporation minus precipitation (should not be confused with the latent heat) (Tragou et al. 1999; Sofianos et al. 2002; Johns et al. 2003). The term GH is radiation flux absorbed by the soil underlying shallowwater regions:

$$
\begin{aligned}
d \bar{Q} & =d \iiint_{V} \rho C_{p} \theta d V, \\
\mathrm{NR} & =\iint_{A}\left(Q_{\mathrm{dsw}}-Q_{\mathrm{usw}}-Q_{\mathrm{ulw}}+Q_{\mathrm{dlw}}\right) d A, \\
\mathrm{LTH}_{\mathrm{in}} & =\iint_{S} \rho C_{p} \theta\left(\mathbf{v}_{\mathrm{in}} \cdot \mathbf{n}\right) d S, \\
\mathrm{LTH}_{\mathrm{out}} & =\iint_{S} \rho C_{p} \theta\left(\mathbf{v}_{\mathrm{out}} \cdot \mathbf{n}\right) d S, \\
\mathrm{WH}_{R} & =\rho C_{p} \theta R, \\
\mathrm{WH}_{E-P} & =\iint_{A}\left(E_{l}-P_{l}\right) \theta d A, \\
\mathrm{GH} & = \begin{cases}Q_{\mathrm{net}} k\left(1-\frac{e^{h / h_{z}}-1}{e-1}\right), & h<h_{z}, \\
0, & h \geq h_{z}\end{cases}
\end{aligned}
$$

where $\mathbf{n}$ is the unit normal vector to the section; $S$ is the area of the transect of the Strait; and $\rho, C_{p}, \theta$, and $V$ are the water density, the specific heat capacity, local water temperature, and total water volume of the Gulf, respectively. The terms $Q_{\mathrm{dsw}}, Q_{\mathrm{usw}}, Q_{\mathrm{ulw}}$, and $Q_{\mathrm{dlw}}$ are local incoming solar radiation, reflected solar radiation, upward longwave radiation, and downward longwave radiation, respectively. The quantities $E_{l}$ and $P_{l}$ are local evaporation and precipitation rates. The term $Q_{\text {net }}$ is the net surface heat flux, $k$ is the empirical absorption coefficient (0.98), and $h_{z}$ is the effective depth $(5 \mathrm{~m})$ for ground heat absorption.

\section{b. Conversion of water and heat fluxes}

To compare relative contributions of different physical processes, water fluxes are converted into equivalent precipitation-evaporation rates over the Gulf. The equivalency between a horizontal water flux $F_{v}$ in units of cubic meters per second into the Gulf and a precipitation rate over the Gulf $P_{r}$ in units of meters per year is

$$
P_{r}=\frac{F_{v}}{A} \times\left(86,400 \times 365 \mathrm{~s} \mathrm{yr}^{-1}\right),
$$

where $A$ is the surface area of the Gulf of $2.3525 \times 10^{11} \mathrm{~m}^{2}$. Similarly, the advective heat fluxes are 
TABLE 3. Basin-averaged, climatological, monthly water flux for the Gulf, 1981-90, estimated by the Gulf-atmosphere model with ECHAM5 atmospheric boundary. Units are in $\mathrm{m} \mathrm{month}^{-1}$.

\begin{tabular}{|c|c|c|c|c|c|c|}
\hline Month & Evaporation & Precipitation & River & Lateral (in) & Lateral (out) & Net \\
\hline January & -0.1325 & 0.0083 & 0.0167 & 3.3833 & -3.2892 & -0.0133 \\
\hline February & -0.1308 & 0.0175 & 0.0217 & 3.4708 & -3.3925 & -0.0133 \\
\hline March & -0.1108 & 0.01 & 0.03 & 3.555 & -3.5317 & -0.0475 \\
\hline April & -0.1125 & 0.0025 & 0.0358 & 3.5575 & -3.4425 & 0.0408 \\
\hline May & -0.1375 & 0.0008 & 0.0308 & 3.4233 & -3.3275 & -0.01 \\
\hline June & -0.1375 & 0 & 0.0183 & 3.3167 & -3.115 & 0.0833 \\
\hline July & -0.1458 & 0 & 0.0108 & 2.8283 & -2.675 & 0.0192 \\
\hline August & -0.17 & 0 & 0.0083 & 2.31 & -2.1283 & 0.0217 \\
\hline September & -0.175 & 0 & 0.0075 & 1.8558 & -1.7167 & -0.0275 \\
\hline October & -0.19 & 0.0075 & 0.0083 & 1.6158 & -1.4175 & 0.0242 \\
\hline November & -0.2017 & 0.0208 & 0.01 & 1.835 & -1.7375 & -0.0733 \\
\hline December & -0.1992 & 0.015 & 0.0133 & 2.5033 & -2.3383 & -0.0067 \\
\hline Average & -0.1533 & 0.0067 & 0.0175 & 2.805 & -2.6758 & 0 \\
\hline
\end{tabular}

converted into the equivalent surface heat fluxes over the Gulf $F_{s}$ in units of watts per square meter by

$$
F_{s}=\frac{\iint \rho C_{p} \theta(\mathbf{v} \cdot \mathbf{n}) d S}{A},
$$

where $\rho, C_{p}, \theta, \mathbf{v}$, and $\mathbf{n}$ are the seawater density, the specific heat capacity, water temperature, velocity, and the unit normal vector to the transect of the Strait (Fig. 1a), respectively.

\section{c. Estimates of water and heat budgets}

The water balance of the Gulf is dominated by the high rate of evaporation and the flux of water through the Strait (Table 3). All other fluxes (rainfall, river discharge, and desalination) are at least one order of magnitude smaller. The rate of evaporation is proportional to the rate of latent heat flux from the sea surface; therefore, the heat and water budgets are tightly coupled in the Gulf. The coupled model simulates an annual evaporation rate of $1.84 \mathrm{~m} \mathrm{yr}^{-1}$ and estimates that the annual influx and outflux of water through the
Strait are equivalent to Gulf-averaged precipitation and evaporation rates of 33.7 and $32.1 \mathrm{~m} \mathrm{yr}^{-1}$. The average depth $h$ of the Gulf water is $38 \mathrm{~m}$. Hence, we estimate that the mean residency time scale $\sigma$ for the Gulf water is about 14 months using the definition $\sigma=A h / L_{\text {in }}$; yet, we recognize that there is a wide range of complex distribution of residency times in the Gulf (Sadrinasab and Kämpf 2004). The lateral net flux simulated by the coupled model is equivalent to a Gulf-averaged precipitation rate of $1.6 \mathrm{~m} \mathrm{yr}^{-1}$. This large net influx of water from the Arabian Sea compensates for $84 \%$ of the high evaporation rate. The model estimates a rainfall rate of $0.085 \mathrm{~m} \mathrm{yr}^{-1}$, mostly during the winter season (Table 3); the very limited rainfall rate in the Gulf was previously estimated between 0.07 (Reynolds 1993) and $0.15 \mathrm{~m} \mathrm{~s}^{-1}$ (Johns et al. 2003), making a small contribution of $4 \%-8 \%$ to the water balance. These estimates by the coupled model, combined with a prescribed river discharge into the Gulf equivalent to a Gulf-averaged precipitation rate of $0.21 \mathrm{~m} \mathrm{yr}^{-1}$ (Saad 1978; Reynolds 1993), are consistent with the estimates from the recent study by Johns et al. (Johns et al. 2003; Hassanzadeh

TABLE 4. As in Table 3, but for the annual-mean water flux

\begin{tabular}{lcccrr}
\hline \hline Year & Evaporation & Precipitation & River & Lateral (in) & Lateral (out) \\
\hline 1981 & -1.84 & 0.12 & 0.21 & 30.34 & -28.90 \\
1982 & -1.89 & 0.04 & 0.21 & 31.82 & -0.06 \\
1983 & -1.86 & 0.12 & 0.21 & 34.39 & -0.07 \\
1984 & -1.82 & 0.07 & 0.21 & 33.59 & -32.84 \\
1985 & -1.86 & 0.07 & 0.21 & 35.12 & -31.79 \\
1986 & -1.86 & 0.04 & 0.21 & 31.89 & -33.78 \\
1987 & -1.84 & 0.02 & 0.21 & 34.59 & -30.50 \\
1988 & -1.85 & 0.17 & 0.21 & 35.59 & -32.68 \\
1989 & -1.80 & 0.03 & 0.21 & 36.52 & -0.24 \\
1990 & -1.81 & 0.15 & 0.21 & 32.69 & -34.23 \\
Average & -1.84 & 0.08 & 0.21 & 33.66 & -0.31 \\
\hline
\end{tabular}




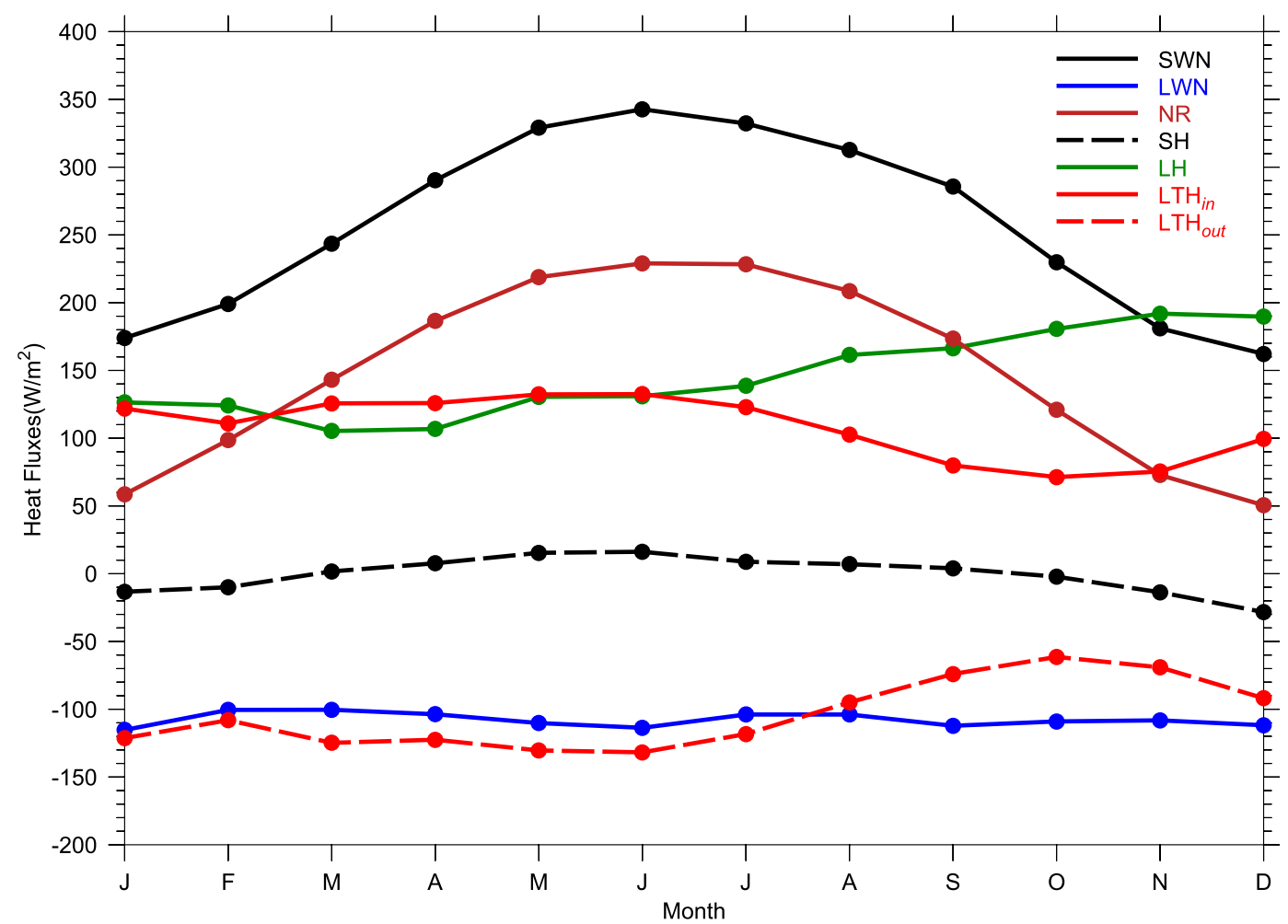

FIG. 8. The model-simulated climatological monthly heat budgets $\left(\mathrm{W} \mathrm{m}^{-2}\right)$ of SWN, LWN, net radiation $(\mathrm{NR}=\mathrm{SWN}-\mathrm{LWN}), \mathrm{SH}, \mathrm{LH}$, lateral heat flux of inflow and outflow through the Strait $\left(\mathrm{LTH}_{\text {in }}\right.$ and $\left.\mathrm{LTH}_{\text {out }}\right)$.

et al. 2012). A detailed estimate of the water budgets at seasonal and annual time scale is presented in Tables 3 and 4 .

The surface heat fluxes are the dominant factors in shaping the seasonal cycle of the water temperature (Fig. 8; Table 5). At the seasonal time scale, the heat balance of the Gulf is dominated by two large vertical fluxes: net surface radiation NR and latent heat flux LH. The total water heat content shows a strong seasonality, which is mainly a reflection of the seasonality in incoming solar radiation and in the latent heat flux (proportional to evaporation). While the seasonal cycle of incoming solar radiation is mainly a reflection of the orbital geometry describing how the earth rotates around the sun, the seasonal cycle of latent heat (evaporation) reflects variability in incoming radiation, temperature, wind, and humidity. The latent heat flux (evaporation) exhibits a seasonal cycle with a minimum

TABLE 5. As in Table 3, but for heat flux. Units are $\mathrm{W} \mathrm{m}^{-2}$.

\begin{tabular}{|c|c|c|c|c|c|c|c|c|c|}
\hline Month & Shortwave & Longwave & Latent & Sensible & Lateral (in) & Lateral (out) & WH & $\mathrm{GH}$ & Net \\
\hline January & 173.9 & -115.3 & -126.4 & -13.3 & 121.9 & -121.3 & -3.7 & -0.1 & -84.4 \\
\hline February & 199.2 & -100.5 & -124.2 & -10.0 & 110.9 & -108.1 & -3.1 & -0.2 & -36.1 \\
\hline March & 243.5 & -100.4 & -105.3 & 1.7 & 125.7 & -124.8 & -2.5 & -0.3 & 37.5 \\
\hline April & 290.3 & -103.7 & -106.8 & 7.7 & 125.9 & -122.5 & -2.9 & -0.4 & 87.5 \\
\hline May & 329.2 & -110.2 & -130.5 & 15.4 & 132.3 & -130.4 & -4.6 & -0.4 & 100.7 \\
\hline June & 342.7 & -113.7 & -131.0 & 16.2 & 132.5 & -131.8 & -5.6 & -0.5 & 108.9 \\
\hline July & 332.2 & -103.9 & -138.6 & 8.8 & 122.9 & -118.3 & -7.0 & -0.5 & 95.7 \\
\hline August & 312.6 & -103.9 & -161.4 & 7.0 & 102.6 & -94.9 & -8.5 & -0.4 & 52.9 \\
\hline September & 285.6 & -112.1 & -166.4 & 4.0 & 79.9 & -74.0 & -8.6 & -0.3 & 8.0 \\
\hline October & 229.9 & -109.1 & -180.6 & -2.2 & 71.3 & -61.4 & -8.4 & -0.2 & -60.7 \\
\hline November & 181.0 & -108.0 & -191.9 & -13.7 & 75.4 & -69.1 & -7.5 & -0.1 & -134.2 \\
\hline December & 162.2 & -111.8 & -189.7 & -28.3 & 99.4 & -91.9 & -6.7 & -0.1 & -166.9 \\
\hline Average & 257.0 & -107.6 & -146.1 & -0.6 & 108.4 & -104.1 & -5.8 & -0.3 & 0.7 \\
\hline
\end{tabular}



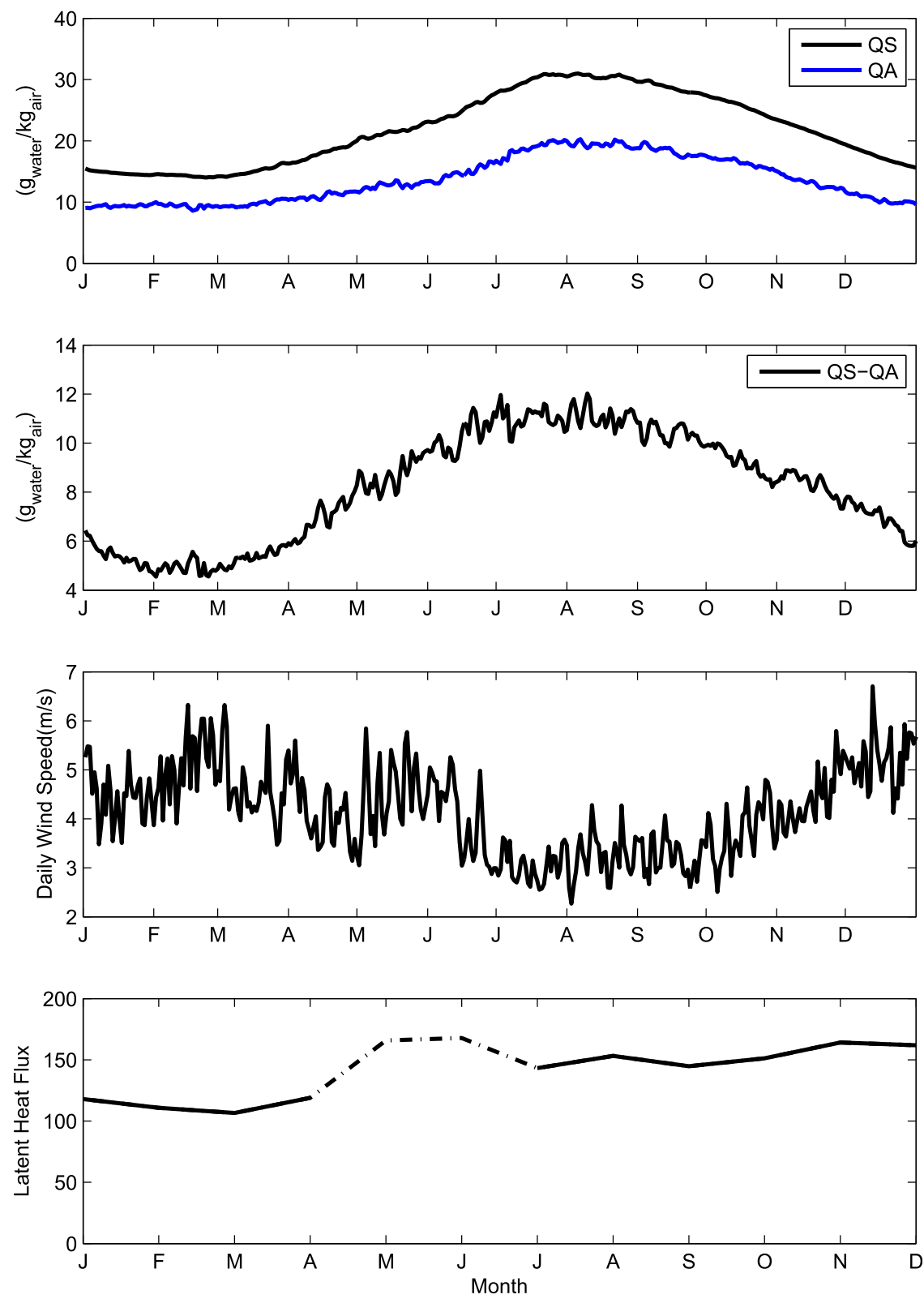

FIG. 9. Gulf-averaged climatological daily mean of (top to bottom) specific humidity $\left(\mathrm{g}_{\text {water }} \mathrm{kg}_{\text {air }}^{-1}\right)$ of air (QA) and the saturated specific humidity over saline seawater (QS), their difference (QS - QA), the daily wind speed, and the estimate of the latent heat flux with the bulk formula [Eq. (12)] using the above climatological daily mean of wind speed and QS - QA.

value in March and April and maximum in November and December; similar cycles are reported in Yao and Johns (2010a,b). Here, we use the bulk formula of the latent heat flux LH to examine possible causes of such a seasonal cycle:

$$
\mathrm{LH}=\rho_{a} L_{e} C_{e} U\left(q_{s}-q_{a}\right),
$$

where $\rho_{a}$ is the air density $\left(\sim 1.2 \mathrm{~kg} \mathrm{~m}^{-3}\right) ; L_{e}$ is the latent heat of evaporation $\left(\sim 2.5 \times 10^{6} \mathrm{~J} \mathrm{~kg}^{-1}\right) ; C_{e}$ is the latent heat transfer coefficient $\left(\sim 1.35 \times 10^{-3}\right) ; U$ and $q_{a}$ are the wind speed and the specific humidity of air; and $q_{s}$ is the saturated specific humidity over saline seawater. The bulk formula implies the wind speed and specific humidity difference at the air-sea interface $\left(q_{s}-q_{a}\right)$ are key factors that control the latent heat flux (evaporation).

The $q_{s}$ is formulated as

$$
q_{s}=0.98 q_{\mathrm{sat}}\left(T_{s}\right)
$$


TABLE 6. As in Table 3, but for annual-mean heat flux. Units are $\mathrm{W} \mathrm{m}^{-2}$.

\begin{tabular}{|c|c|c|c|c|c|c|c|c|c|}
\hline Year & Shortwave & Longwave & Latent & Sensible & Lateral (in) & Lateral (out) & WH & $\mathrm{GH}$ & Net \\
\hline 1981 & 261.3 & -112.0 & -145.7 & 0.1 & 99.1 & -95.0 & -5.5 & -0.3 & 1.8 \\
\hline 1982 & 258.5 & -109.3 & -149.6 & 1.0 & 103.7 & -99.8 & -5.9 & -0.3 & -1.9 \\
\hline 1983 & 255.5 & -105.1 & -147.2 & 0.9 & 111.3 & -107.2 & -5.6 & -0.3 & 2.1 \\
\hline 1984 & 255.9 & -107.1 & -144.2 & -1.9 & 107.5 & -101.9 & -5.7 & -0.3 & 2.4 \\
\hline 1985 & 257.5 & -107.2 & -147.5 & -1.5 & 112.1 & -107.9 & -5.7 & -0.3 & -0.7 \\
\hline 1986 & 260.1 & -108.0 & -147.7 & 0.3 & 103.3 & -99.8 & -5.8 & -0.3 & 1.7 \\
\hline 1987 & 259.7 & -110.2 & -145.7 & 0.0 & 111.3 & -106.6 & -5.9 & -0.3 & 2.1 \\
\hline 1988 & 252.2 & -106.5 & -146.8 & -2.8 & 114.7 & -111.4 & -5.5 & -0.3 & -6.5 \\
\hline 1989 & 259.1 & -110.1 & -142.7 & -0.5 & 116.2 & -110.7 & -5.6 & -0.3 & 5.2 \\
\hline 1990 & 248.7 & -101.7 & -143.5 & -0.9 & 104.8 & -100.2 & -5.4 & -0.3 & 1.4 \\
\hline Average & 257.0 & -107.6 & -146.1 & -0.6 & 108.4 & -104.1 & -5.7 & -0.3 & 0.7 \\
\hline
\end{tabular}

where $T_{s}$ is the sea surface temperature and $q_{\text {sat }}$ is the saturation specific humidity for pure water at $T_{s}$. The factor of 0.98 is an approximation to take into account the reduction of vapor pressure caused by a typical ocean salinity (Fairall et al. 1996), with $q_{\text {sat }}$ in a formula in (Buck 1981)

$$
\begin{aligned}
q_{\text {sat }}= & \frac{0.622 e_{s}}{P_{a}-0.378 e_{s}}, \\
e_{s}= & {\left[1.0007+\left(3.46 \times 10^{-6} P_{a}\right)\right] } \\
& \times 6.1121 \exp \left(\frac{17.502 T_{s}}{240.97+T_{s}}\right),
\end{aligned}
$$

where $P_{a}$ is the air pressure. Figure 9 (top) shows the Gulf-averaged climatologically daily value of $q_{s}, q_{a}$, and $q_{s}-q_{a}$. With an arid climate, the terms $q_{s}$ and $q_{a}$ are small between $\sim(15-30)$ and 10 $15 \mathrm{~g}_{\text {water }} \mathrm{kg}_{\text {air }}^{-1}$ over the Gulf, respectively. Their difference exhibits a minimum value in March and maximum in August. The wind speed (Fig. 9), on the other hand, shows a seasonal cycle with strong wind of $\sim 6 \mathrm{~m} \mathrm{~s}^{-1}$ during the winter seasons and weaker wind of $\sim 3 \mathrm{~m} \mathrm{~s}^{-1}$ during July to September. Although this simple analysis would not be sufficient to explain the nonlinear spatiotemporal variability of the latent heat flux in the coupled system, it indicates the high latent heat during November and December is caused by the combination of strong wind as well as relatively large humidity gradient. The low latent heat flux during March and April is because of the small air-sea humidity difference. The horizontal distributions of the monthly climatology of wind and humidity are presented in the supplemental information in Figs. S3-S5 in the supplemental material. Figure 9 (bottom) shows that the latent heat estimated with the simple bulk formula [Eq. (12)] using the climatological daily value of $q_{s}-q_{a}$ and daily wind speed (Fig. 9). The results show that the simple bulk calculation reproduces to some extent the seasonal pattern (Fig. 8) with the outliers of May and June. For a coupled nonlinear system, we do not expect that the dynamics could be fully explained by a simple linear combination of the domain-averaged daily wind and humidity gradient. Indeed, Fig. 9, along with other results, indicates the complexity of the Gulf system, which can only be resolved with a two-way, coupled, oceanatmosphere model.

At the annual time scale, however, the heat balance is dictated by several small fluxes. The coupled model simulation suggests that the Gulf receives annual net surface heat flux from the atmosphere of $+2.7 \mathrm{~W} \mathrm{~m}^{-2}$ and lateral heat flux through the Strait equivalent to a surface heat flux over the Gulf of $4.1 \mathrm{Wm}^{-2}$. These two small fluxes are balanced to a large degree by the heat loss from the Gulf (equivalent to $-5.8 \mathrm{~W} \mathrm{~m}^{-2}$ ) associated with the heat content carried by net water loss (i.e., $\mathrm{WH}_{E-P}-\mathrm{WH}_{R}$ ). In addition, the solar radiation penetrates through shallow water in coastal areas resulting in small but significant absorption by the underlying soil $\left(0.3 \mathrm{~W} \mathrm{~m}^{-2}\right)$. This estimate is quite uncertain, since we are not aware of any direct measurements of this flux. A detailed estimate of the heat budgets at seasonal and annual time scales is presented in Tables 5 and 6.

\section{Discussion}

In this study, we constrain our model using atmospheric boundary conditions from simulations by general circulation model ECHAM5. However, a fair question is how reliable are our model results since they were constrained by lateral boundary conditions from a model simulation rather than by observations directly. To address this question, we have conducted the same coupled simulation experiments with lateral boundary conditions constrained by the ERA-40 reanalysis data. The results in these two cases agree very well, which gives us confidence in our estimates of heat and water budgets of the Gulf (Fig. 10). Detailed estimates of water and heat budgets at seasonal and annual time scales in the simulation experiments with ERA-40 boundary condition are presented in Tables A1-A4 in the appendix. 

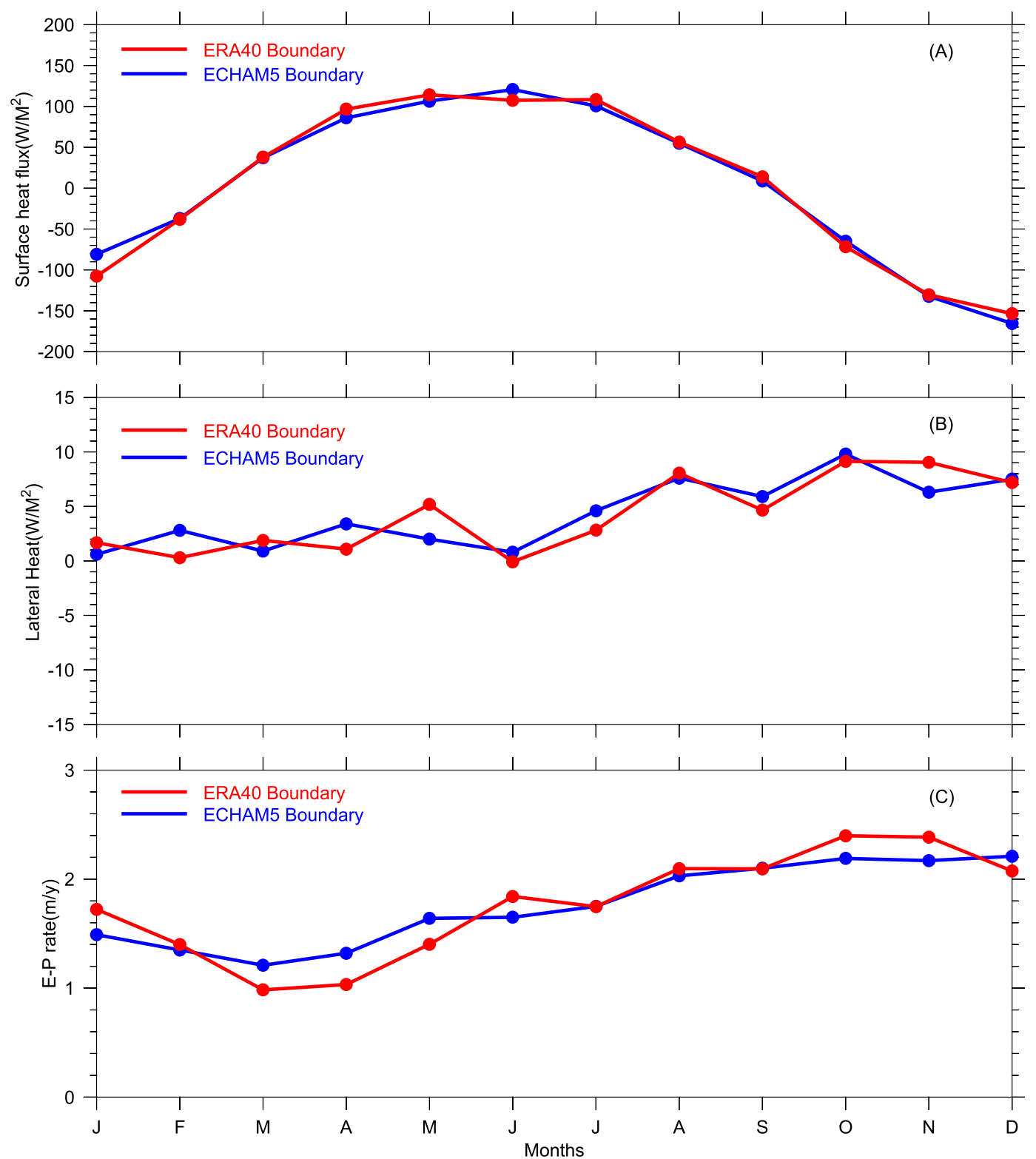

FIG. 10. Sensitivity analysis. The comparison of the coupled simulation results when lateral atmospheric boundary conditions are constrained by ECHAM5 (blue) and ERA-40 (red). (a) Decadal-averaged monthly net surface heat flux over the Gulf. (b) Decadal-averaged monthly lateral heat transport through the Strait (converted into equivalent surface heat flux over the Gulf). (c) Decadal-averaged monthly evaporation - precipitation over the Gulf.

The fact that only a coupled Gulf-atmosphere model succeeded in reproducing the observed SST climatology and demonstrated significant skill in simulating the heat budget of the Gulf without any flux adjustments is consistent with the hypothesis of a significant two-way, air-sea coupled process over the Gulf. Here, we show evidence for the existence of a strong negative air-sea feedback process over the Gulf. This feedback process tends to stabilize the system through a local "SST-latent heat" adjustment: a positive (negative) perturbation of SST causes an increase (decrease) of the saturation specific humidity at the sea surface and hence increases (decreases) the specific humidity gradient at the air-sea interface, which results in an increase (decrease) of the loss of latent heat from the Gulf, therefore suppressing the perturbation of SST. This negative feedback can be clearly identified in a simple numerical experiment. A perturbation was imposed to the SST by artificially increasing the water temperature by $1^{\circ} \mathrm{C}$ in the upper $5 \mathrm{~m}$, the coupled system recovered and restored the SST field in a very short 

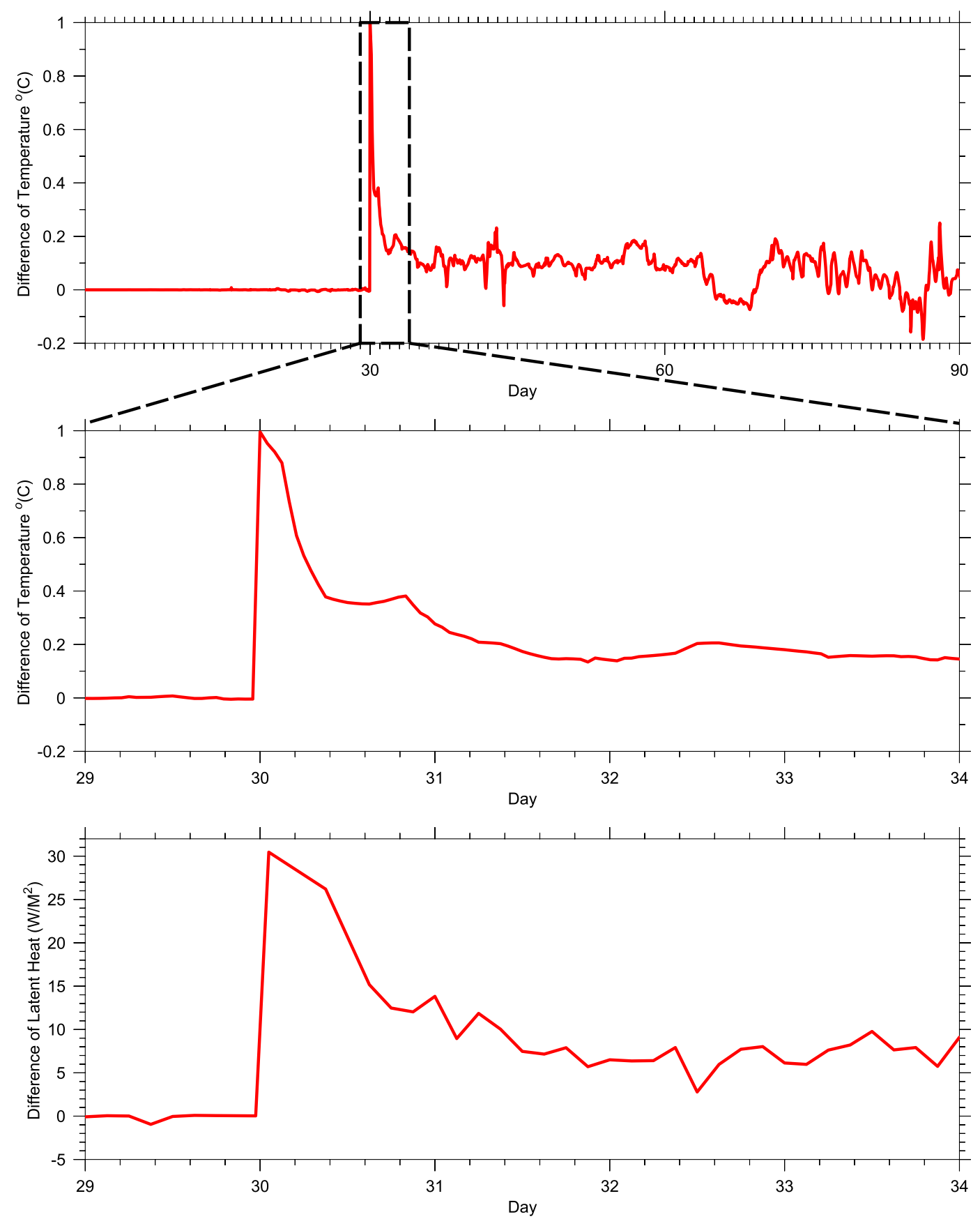

FIG. 11. The responses of the coupled system to the SST perturbation. (top) Restoration of the SST over the Gulf after its perturbation driven by the negative feedback process. (middle) As in the top, but zoomed-in to a 5-day time window. (bottom) Changes in latent heat in response to the SST perturbation.

$e$-folding time scale of $\sim 12 \mathrm{~h}$ (Fig. 11). The adjustment of latent heat flux responds with a peak value of $\sim 30 \mathrm{~W} \mathrm{~m}^{-2}$ immediately after the SST perturbation, and the magnitude of latent heat flux adjustment decreases over time as the SST is restored toward its equilibrium state. Therefore, the ability of the coupled model to simulate this negative feedback process, which allows SST and surface heat flux to directly interact with each other, is the main factor that made it possible to achieve consistent estimates of the heat budget and SST over the Gulf and advance our understanding of this system.

It should be pointed out that evaporative cooling is not necessarily the only mechanism responsible for local negative air-sea feedbacks, depending on characteristics of a 


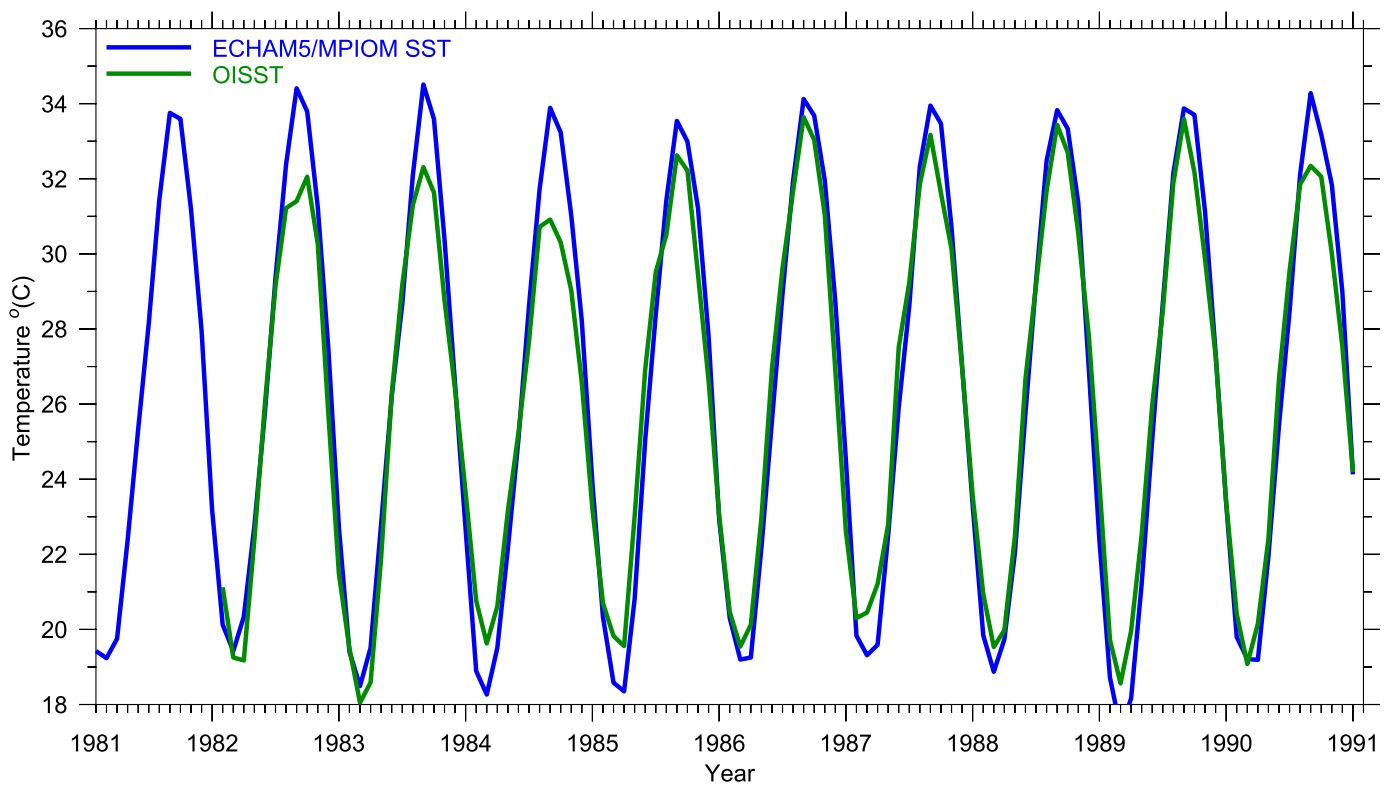

FIG. 12. Time series of the Gulf-averaged ECHAM5/MPIOM SST (blue) used in the uncoupled, atmosphere-only model, compared to the OISST (green, available from 1982). Notice a significant overestimation in ECHAM5/ MPIOM SST during the warm seasons, particularly in the first $5 \mathrm{yr}$.

coupled system. Xue et al. (2014) discussed negative feedback mechanisms in the tropical Maritime Continent, where the evaporative cooling and low-level cloud feedback both play dominant roles in controlling the localscale, negative, air-sea feedback process. The contribution of cloud feedback to the adjustment of the surface heat flux is negligible in the Gulf, as the cloud cover is very limited and evaporation is so strong in the Gulf. In the SST perturbation experiment, the incoming solar radiation remains nearly unchanged because of the extremely low coverage of clouds. This is significantly different from the case in the humid tropical region with intensive convection, where the increased inputs of heat and moisture into the lower atmosphere increase the formation of lowlevel clouds, which act as a shield preventing incoming solar radiation from reaching the sea surface and accounts for up to $\sim 40 \%$ of the total adjustment of surface heat flux (Xue et al. 2014). In addition, the adjustments of sensible

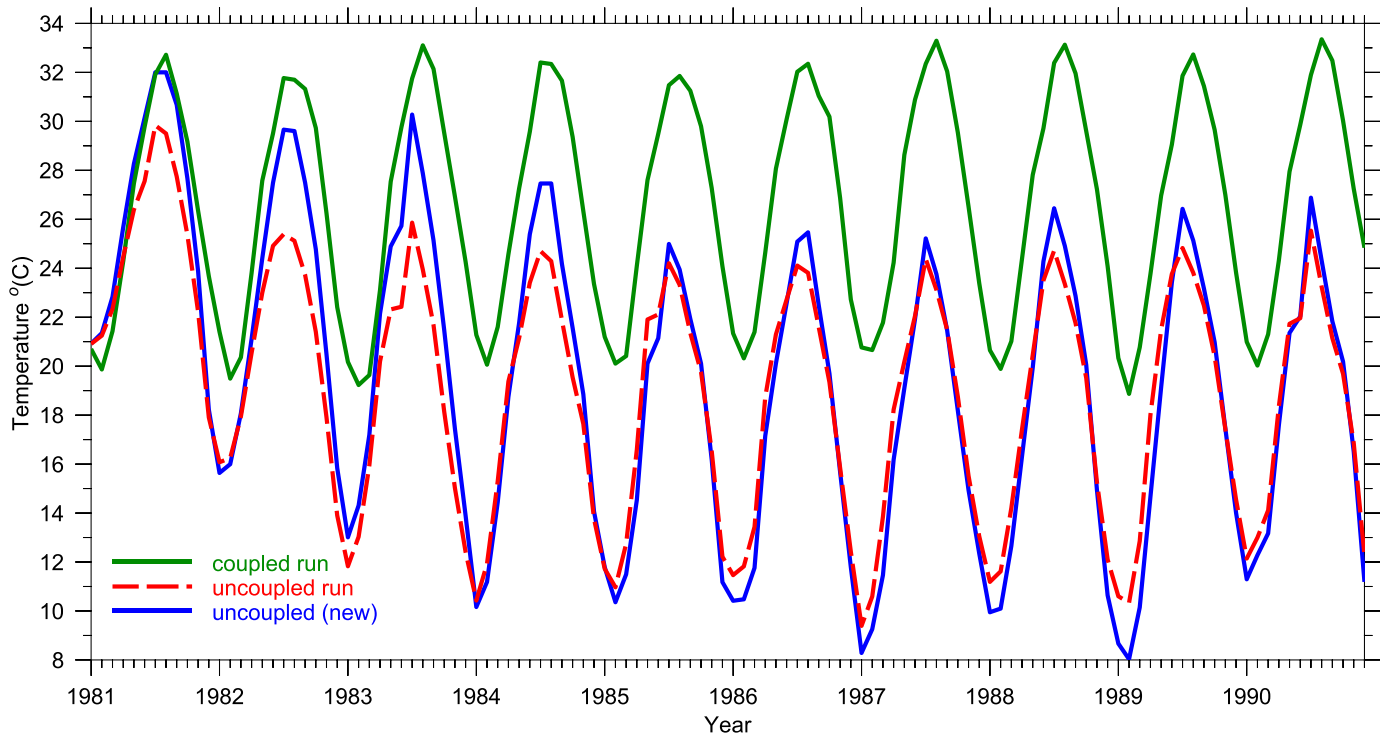

FIG. 13. The time evolution of the Gulf-averaged SST. The uncoupled atmosphere-only simulation was rerun with the adjusted SST to generate surface meteorological fields, which were then used to drive the uncoupled ocean model to simulate SST (blue), in comparison with the original uncoupled simulation (red) and coupled simulation (green) as shown in Fig. 3. 
TABLE A1. Basin-averaged, climatological, monthly heat flux for the Gulf, 1981-90, estimated by the Gulf-atmosphere model with ERA-40 atmospheric boundary. Units are $\mathrm{W} \mathrm{m}^{-2}$.

\begin{tabular}{lcccccrrrr}
\hline \hline \multicolumn{1}{c}{ Month } & Shortwave & Longwave & Latent & Sensible & Lateral (in) & Lateral (out) & WH & GH & Net \\
\hline January & 165.3 & -104.1 & -147.9 & -19.7 & 109.7 & -108.1 & -4.5 & -0.1 & -109.4 \\
February & 202.6 & -101.1 & -127.5 & -11.5 & 115.9 & -115.6 & -3.3 & -0.2 & -40.7 \\
March & 230.3 & -89.2 & -102.0 & 1.1 & 130.2 & -128.3 & -2.0 & -0.3 & 39.9 \\
April & 271.4 & -89.2 & -90.5 & 8.4 & 124.3 & -123.2 & -2.1 & -0.4 & 98.7 \\
May & 312.0 & -95.9 & -113.3 & 12.3 & 130.0 & -124.8 & -4.0 & -0.4 & 115.9 \\
June & 341.8 & -110.7 & -146.0 & 15.2 & 126.3 & -126.3 & -6.6 & -0.5 & 93.0 \\
July & 329.7 & -95.0 & -138.7 & 9.3 & 125.2 & -122.4 & -7.1 & -0.5 & 100.5 \\
August & 310.3 & -93.7 & -166.2 & 5.6 & 107.9 & -99.8 & -9.0 & -0.4 & 54.7 \\
September & 282.3 & -102.5 & -166.1 & 2.1 & 89.2 & -84.6 & -8.7 & -0.4 & 11.4 \\
October & 233.7 & -108.2 & -190.6 & -1.9 & 73.4 & -64.3 & -9.4 & -0.3 & -67.5 \\
November & 183.0 & -107.1 & -192.3 & -11.3 & 70.5 & -61.4 & -8.4 & -0.2 & -127.2 \\
December & 154.0 & -104.0 & -180.2 & -24.6 & 86.3 & -79.1 & -6.4 & -0.1 & -154.1 \\
Average & 251.4 & -100.1 & -146.8 & -1.2 & 107.4 & -103.2 & -6.0 & -0.3 & 1.3 \\
\hline
\end{tabular}

heat $\left(2.2 \mathrm{~W} \mathrm{~m}^{-2}\right)$ and upward longwave radiation $\left(1.5 \mathrm{~W} \mathrm{~m}^{-2}\right)$ in response to SST perturbation are also one order of magnitude smaller than the adjustment of latent heat due to the strong evaporation and a low Bowen ratio in the Gulf. This is again regional climate dependent; another example is the Laurentian Great Lakes region where the latent heat and sensible heat play comparably important roles in controlling the net surface heat flux in the fall seasons, yet both are negligible during summertime.

Furthermore, as the SST is as much a reflection of the surface flux as being a forcing of the flux in a shallowwater system, the high-frequency variability of the SST must be resolved (using a coupled model) to be consistent with the response time scale of the local air-sea feedback process, otherwise systematic biases may occur (Xue et al. 2014). This suggests that a prescription of the monthly or weekly mean state of SST is inadequate to resolve the strongly coupled Gulf system. To test this hypothesis, first we conducted a retrospective analysis for the prescribed SST used in the atmosphere-only model, which shows a significantly overestimated temperature than the observed OISST during the warm (high temperature) seasons, particularly in the first $5 \mathrm{yr}$ (Fig. 12). This indicates that overestimated SSTs specified in the uncoupled, atmosphere-only model can result in overestimates of the latent heat flux and therefore the net surface heat loss from the Gulf. Second, we made a correction to the prescribed SST by removing the basinaveraged monthly mean bias. In such a way, we adjusted the Gulf-averaged mean state of the prescribed SST used in the uncoupled atmospheric model while retaining its original spatial variability and temporal resolution. Third, we reran the uncoupled simulation of the MRCM with the adjusted SSTs to generate surface meteorological fields, which were then used to drive the uncoupled FVCOM model. The results show improvements of the FVCOMsimulated SST during summer seasons in the first $5 \mathrm{yr}$ after the large warm bias $\left(1^{\circ}-3^{\circ} \mathrm{C}\right)$ was corrected. Despite the improvement, the cold bias cannot be eliminated in the uncoupled simulation (Fig. 13). The result is consistent with our hypothesis on the critical role of resolving coupled airsea feedbacks using a coupled model since the SST is only one of the key factors (e.g., wind and humidity) determining the surface heat flux, which in turn directly and nonlinearly influence the variation of SST.

Salinity of the Gulf depends on the rate of evaporation as well as the net exchange of salt through the Strait. If increases in evaporation are accompanied by negligible

TABLE A2. As in Table A1, but for annual-mean heat flux.

\begin{tabular}{|c|c|c|c|c|c|c|c|c|c|}
\hline Year & Shortwave & Longwave & Latent & Sensible & Lateral (in) & Lateral (out) & WH & $\mathrm{GH}$ & Net \\
\hline 1981 & 252.6 & -101.6 & -142.4 & 1.7 & 93.5 & -89.1 & -5.5 & -0.3 & 8.4 \\
\hline 1982 & 241.0 & -94.3 & -145.9 & -4.0 & 103.1 & -99.4 & -5.9 & -0.3 & -5.1 \\
\hline 1983 & 251.4 & -98.7 & -145.5 & -2.9 & 103.1 & -98.5 & -5.6 & -0.3 & 2.7 \\
\hline 1984 & 251.6 & -101.9 & -148.1 & -0.6 & 115.2 & -110.7 & -5.7 & -0.3 & -0.8 \\
\hline 1985 & 254.6 & -101.9 & -147.2 & -0.8 & 106.8 & -102.6 & -5.7 & -0.3 & 2.5 \\
\hline 1986 & 249.6 & -98.9 & -148.9 & -2.4 & 108.1 & -104.0 & -5.8 & -0.3 & -2.9 \\
\hline 1987 & 255.6 & -102.0 & -149.1 & 0.1 & 115.0 & -111.0 & -5.9 & -0.3 & 1.9 \\
\hline 1988 & 251.0 & -99.1 & -147.0 & -0.2 & 110.6 & -105.8 & -5.5 & -0.3 & 3.0 \\
\hline 1989 & 249.6 & -100.2 & -144.6 & -3.1 & 112.2 & -107.8 & -5.6 & -0.3 & 0.0 \\
\hline 1990 & 256.6 & -101.8 & -149.2 & 0.0 & 106.5 & -102.6 & -5.4 & -0.3 & 2.8 \\
\hline Average & 251.4 & -100.1 & -146.8 & -1.2 & 107.4 & -103.2 & -5.7 & -0.3 & 1.3 \\
\hline
\end{tabular}


TABLE A3. As in Table A1, but for water flux. Units are m month ${ }^{-1}$.

\begin{tabular}{|c|c|c|c|c|c|c|}
\hline Month & Evaporation & Precipitation & River & Lateral (in) & Lateral (out) & Net \\
\hline January & -0.1558 & 0.0117 & 0.0167 & 2.9433 & -2.7867 & 0.0292 \\
\hline February & -0.1342 & 0.0175 & 0.0217 & 3.545 & -3.53 & -0.0792 \\
\hline March & -0.1075 & 0.025 & 0.03 & 3.615 & -3.5433 & 0.0183 \\
\hline April & -0.095 & 0.0092 & 0.0358 & 3.4817 & -3.3983 & 0.0333 \\
\hline May & -0.1192 & 0.0025 & 0.0308 & 3.3208 & -3.2008 & 0.0342 \\
\hline June & -0.1533 & 0 & 0.0183 & 3.1542 & -3.0183 & 0.0008 \\
\hline July & -0.1458 & 0 & 0.0108 & 2.8442 & -2.6525 & 0.0567 \\
\hline August & -0.175 & 0 & 0.0083 & 2.3983 & -2.2008 & 0.0317 \\
\hline September & -0.175 & 0 & 0.0075 & 2.0333 & -1.9083 & -0.0417 \\
\hline October & -0.2 & 0.0008 & 0.0083 & 1.63 & -1.4542 & -0.0158 \\
\hline November & -0.2025 & 0.0033 & 0.01 & 1.6892 & -1.5375 & -0.0375 \\
\hline December & -0.1892 & 0.0167 & 0.0133 & 2.1058 & -1.9967 & -0.0508 \\
\hline Average & -0.1542 & 0.0075 & 0.0175 & 2.73 & -2.6025 & -0.0017 \\
\hline
\end{tabular}

change in the salt flux through the Strait, that would lead to higher salinity. However, if the resulting net exchange of salt flux through the strait is negative and dominant (from the Gulf to the Arabian Sea), then increases in evaporation may be accompanied by decreases in salinity. This can be seen in the net salt flux adjustment $S_{\text {net }}$ through the Strait:

$$
S_{\text {net }}=S_{\text {in }} \Delta L_{\text {in }}-S_{\text {out }} \Delta L_{\text {out }},
$$

where $\Delta L_{\text {in }}$ and $\Delta L_{\text {out }}$ are the changes in the inflow and flow accompanied by the increase in evaporation. The term $S_{\text {net }}$ can possibly be either positive or negative even when $\Delta L_{\text {in }}>\Delta L_{\text {out }}$ on the condition that inflow is fresher than the outflow $\left(S_{\text {in }}<S_{\text {out }}\right)$, depending on the flow/buoyancy structure in the Strait.

\section{Summary}

In our coupled system of models, the variables' SST, surface flux, and wind are not prescribed but predicted by the model. The same variables are allowed to evolve freely with two-way interactions. The fact that our coupled model succeeds in simulating the SST climatology with reasonable accuracy adds significant credibility to corresponding model estimations of the surface heat fluxes and heat budget. This close coupling of SST to the net surface heat flux highlights the need for accurate estimation of the surface heat budget of the Gulf. Using the first-of-its-kind model built for the Gulf, this study illustrates that the most suitable modeling approach for regional climate studies in this region is to consistently simulate water and heat fluxes through the use of a laterally constrained and vertically coupled Gulf-atmosphere model.

The reason behind the success of the coupled model is in its ability to simulate the close coupling of the two-way exchanges across the air-water interface. A strong negative feedback couples temperatures of the Gulf and the lower atmosphere through adjustments in latent heat flux at time scales of $\sim 12 \mathrm{~h}$. Uncoupled models suffer from a cold drift due to the absence of this negative feedback.

The heat and water budgets of the Gulf are dominated by evaporation (latent heat flux) and lateral exchange of water (heat) with the Arabian Sea. We estimate that the Gulf acts as a sink of heat for the atmosphere $\left(+3 \mathrm{~W} \mathrm{~m}^{-2}\right)$ and the annual evaporation from the Gulf is $1.84 \mathrm{~m} \mathrm{yr}^{-1}$. The annual influx and outflux of water through the Strait of Hormuz between the Gulf and the Arabian Sea are equivalent to Gulf-averaged precipitation and evaporation rates of 33.7 and $32.1 \mathrm{~m} \mathrm{yr}^{-1}$. The average depth of the

TABLE A4. As in Table A1, but annual-mean water flux. Units are $\mathrm{m} \mathrm{yr}^{-1}$.

\begin{tabular}{lcccrr}
\hline \hline Year & Evaporation & Precipitation & River & Lateral (in) & Lateral (out) \\
\hline 1981 & -1.80 & 0.03 & 0.21 & 28.36 & -26.93 \\
1982 & -1.84 & 0.26 & 0.21 & 31.64 & -30.27 \\
1983 & -1.84 & 0.09 & 0.21 & 31.94 & -30.12 \\
1984 & -1.87 & 0.08 & 0.21 & 35.00 & -0.00 \\
1985 & -1.86 & 0.04 & 0.21 & 32.44 & -33.21 \\
1986 & -1.88 & 0.08 & 0.21 & 33.11 & -30.87 \\
1987 & -1.88 & 0.06 & 0.21 & 34.94 & -31.61 \\
1988 & -1.85 & 0.07 & 0.21 & 33.68 & -33.41 \\
1989 & -1.82 & 0.09 & 0.21 & 34.54 & -31.92 \\
1990 & -1.88 & 0.06 & 0.21 & 31.97 & -0.04 \\
Average & -1.85 & 0.09 & 0.21 & 32.76 & -33.10 \\
\hline
\end{tabular}


Gulf water is $\sim 38 \mathrm{~m}$. Hence, we estimate that the mean residency time scale for the entire Gulf is $\sim 14$ months.

Acknowledgments. This work was funded under the Cooperative Agreement between the Masdar Institute of Science and Technology (Masdar Institute), Abu Dhabi, UAE, and the Massachusetts Institute of Technology (MIT), Cambridge, MA, USA-Reference 02/ MI/MI/CP/11/07633/GEN/G/00. Xue's research was also supported by the Michigan Tech Research Excellence Fund Research Seed Grant. This is also research (Contribution No. 19) of the Great Lakes Research Center at Michigan Tech. The authors thank Dr. Marc Marcella and Dr. Im Eun Soon for their help with atmosphere-only model configuration. We also thank three anonymous reviewers' valuable comments, which have greatly helped us to improve this research. E. E. and P. X. conceived and designed the experiments; P. X. performed the modeling experiments; E. E. and P. X. analyzed the data; and E. E. and P. X. cowrote the paper.

\section{APPENDIX}

\section{Estimates of Water and Heat Fluxes from GARM with ERA-40 Atmospheric Boundary}

Basin-averaged, climatological, monthly and annual heat and water fluxes for the Gulf, 1981-90, estimated by the Gulf-atmosphere model with ERA-40 atmospheric boundary (Tables A1-A4).

\section{REFERENCES}

Abualnaja, Y., 2009: Estimation of the net surface heat flux in the Arabian Gulf based on the equilibrium temperature. J. King Abdulaziz Univ. Mar. Sci., 20, 21-29, doi:10.4197/Mar.20-1.2.

Ahmad, F., and S. A. R. Sultan, 1991: Annual mean surface heat fluxes in the Arabian Gulf and the net heat transport through the Strait of Hormuz. Atmos.-Ocean, 29, 54-61, doi:10.1080/ 07055900.1991 .9649392$.

Antonov, I., 2010: Salinity. Vol. 2, World Ocean Atlas 2009, NOAA Atlas NESDIS 69, 184 pp.

Beardsley, R. C., C. Chen, and Q. Xu, 2013: Coastal flooding in Scituate (MA): A FVCOM study of the 27 December 2010 nor'easter. J. Geophys. Res. Oceans, 118, 6030-6045, doi:10.1002/2013JC008862.

Buck, A. L., 1981: New equations for computing vapor pressure and enhancement factor. J. Appl. Meteor., 20, 1527-1532, doi:10.1175/1520-0450(1981)020<1527:NEFCVP $>2.0 . \mathrm{CO} ; 2$.

Carton, J. A., and B. S. Giese, 2008: A reanalysis of ocean climate using Simple Ocean Data Assimilation (SODA). Mon. Wea Rev., 136, 2999-3017, doi:10.1175/2007MWR1978.1.

Chao, S., T. W. Kao, and K. R. Al-Hajri, 1992: A numerical investigation of circulation in the Arabian Gulf. J. Geophys. Res., 97, 11 219-11236, doi:10.1029/92JC00841.

Chen, C., H. Liu, and R. C. Beardsley, 2003: An unstructured grid, finitevolume, three-dimensional, primitive equations ocean model: Application to coastal ocean and estuaries. J. Atmos. Oceanic
Technol., 20, 159-186, doi:10.1175/1520-0426(2003)020<0159: AUGFVT $>2.0 . \mathrm{CO} ; 2$.

, R. C. Beardsley, and G. Cowles, 2006: An unstructured grid, Finite-Volume Coastal Ocean Model (FVCOM) system. Oceanography, 19, 78-89, doi:10.5670/oceanog.2006.92.

and Coauthors, 2008: Physical mechanisms for the offshore detachment of the Changjiang diluted water in the East China Sea. J. Geophys. Res., 113, C02002, doi:10.1029/2006JC003994.

— Z. Zai, R. C. Beardsley, J. Sasaki, J. Lin, H. Lin, R. Ji, and Y. Sun, 2014: The March 11, 2011 Tōhoku M9.0 earthquakeinduced tsunami and coastal inundation along the Japanese coast: A model assessment. Prog. Oceanogr., 123, 84-104, doi:10.1016/j.pocean.2014.01.002.

Cowles, G. W., S. J. Lentz, C. Chen, Q. Xu, and R. C. Beardsley, 2008: Comparison of observed and model-computed low frequency circulation and hydrography on the New England shelf. J. Geophys. Res., 113, C09015, doi:10.1029/ 2007JC004394.

Evans, J. P., R. B. Smith, and R. J. Oglesby, 2004: Middle East climate simulation and dominant precipitation processes. Int. J. Climatol., 24, 1671-1694, doi:10.1002/joc.1084.

Fairall, C. W., E. F. Bradley, D. P. Rogers, J. B. Edson, and G. S. Young, 1996: Bulk parameterization of air-sea fluxes for tropical ocean-global atmosphere coupled-ocean atmosphere response experiment. J. Geophys. Res., 101, 3747-3764, doi:10.1029/95JC03205.

Gianotti, R. L., 2013: Convective cloud and rainfall processes over the Maritime Continent: Simulation and analysis of the diurnal cycle. Ph.D. thesis, Massachusetts Institute of Technology, 307 pp.

, and E. A. B. Eltahir, 2014a: Regional climate modeling over the Maritime Continent. Part I: New parameterization for convective cloud fraction. J. Climate, 27, 1488-1503, doi:10.1175/JCLI-D-13-00127.1.

, and — , 2014b: Regional climate modeling over the Maritime Continent. Part II: New parameterization for autoconversion of convective rainfall. J. Climate, 27, 15041523, doi:10.1175/JCLI-D-13-00171.1.

Giorgi, F., and L. O. Mearns, 1999: Introduction to special section: Regional climate modeling revisited. J. Geophys. Res., 104, 6335-6352, doi:10.1029/98JD02072.

Hamza, W., and M. Munawar, 2009: Protecting and managing the Arabian Gulf: Past, present and future. Aquat. Ecosyst. Health Manage., 12, 429-439, doi:10.1080/14634980903361580.

Hassanzadeh, S., F. Hosseinibalam, and A. Rezaei-Latifi, 2011: Numerical modelling of salinity variations due to wind and thermohaline forcing in the Persian Gulf. Appl. Math. Modell., 35, 1512-1537, doi:10.1016/j.apm.2010.09.029.

$\longrightarrow,-$, and — 2012: Three-dimensional numerical modeling of the water exchange between the Persian Gulf and the Gulf of Oman through the Strait of Hormuz. Oceanol. Hydrobiol. Stud., 41, 85-98, doi:10.2478/s13545-012-0010-6.

Hastenrath, S., P. J. Lamb, and L. L. Greischar, 1979: Climatic Atlas of the Indian Ocean: The Oceanic Heat Budget. University of Wisconsin Press, $93 \mathrm{pp}$

Johns, W. E., F. Yao, D. B. Olson, S. A. Josey, J. P. Grist, and D. A. Smeed, 2003: Observations of seasonal exchange through the Straits of Hormuz and the inferred heat and freshwater budgets of the Persian Gulf. J. Geophys. Res., 108, 3391, doi:10.1029/2003JC001881.

Kämpf, J., and M. Sadrinasab, 2006: The circulation of the Persian Gulf: A numerical study. Ocean Sci., 2, 27-41, doi:10.5194/ os-2-27-2006. 
Locarnini, A., 2010: Temperature. Vol. 1, World Ocean Atlas 2009, NOAA Atlas NESDIS 68, $184 \mathrm{pp}$.

Marcella, M. P., and E. A. B. Eltahir, 2008: The hydroclimatology of Kuwait: Explaining the variability of rainfall at seasonal and interannual time scales. J. Hydrometeor., 9, 1095-1105, doi:10.1175/2008JHM952.1.

— , and — 2012: Modeling the summertime climate of Southwest Asia: The role of land surface processes in shaping the climate of semiarid regions. J. Climate, 25, 704-719, doi:10.1175/2011JCLI4080.1.

— and —, 2014: Introducing an irrigation scheme to a regional climate model: A case study over West Africa. J. Climate, 27, 5708-5723, doi:10.1175/JCLI-D-13-00116.1.

Mellor, G. L., and T. Yamada, 1982: Development of a turbulence closure model for geophysical fluid problems. Rev. Geophys., 20, 851-875, doi:10.1029/RG020i004p00851.

Meshal, A. H., and H. M. Hassan, 1986: Evaporation from the coastal waters of the central part of the Gulf. Arab Gulf J. Sci. Res., 4, 649-655.

Pal, J. S., and Coauthors, 2007: Regional climate modeling for the developing world: The ICTP RegCM3 and RegCNET. Bull. Amer. Meteor. Soc., 88, 1395-1409, doi:10.1175/ BAMS-88-9-1395

Prasad, T. G., M. Ikeda, and S. P. Kumar, 2001: Seasonal spreading of the Persian Gulf water mass in the Arabian Sea. J. Geophys. Res., 106, 17 059-17 071, doi:10.1029/2000JC000480.

Privett, D. W., 1959: Monthly charts of evaporation from the N. Indian Ocean (including the Red Sea and the Persian Gulf). Quart. J. Roy. Meteor. Soc., 85, 424-428, doi:10.1002/ qj.49708536614.

Reynolds, R. M., 1993: Physical oceanography of the Gulf, Strait of Hormuz, and the Gulf of Oman-Results from the Mt Mitchell expedition. Mar. Pollut. Bull., 27, 35-59, doi:10.1016/ 0025-326X(93)90007-7.

Reynolds, R. W., T. M. Smith, C. Liu, D. B. Chelton, K. S. Casey, and M. G. Schlax, 2007: Daily high-resolution-blended analyses for sea surface temperature. J. Climate, 20, 54735496, doi:10.1175/2007JCLI1824.1.

Saad, M. A. H., 1978: Seasonal variations of some physicochemical conditions of Shatt al-Arab estuary, Iraq. Estuarine Coastal Mar. Sci., 6, 503-513, doi:10.1016/0302-3524(78)90027-0.

Sabziparvar, A. A., S. H. Mirmasoudi, H. Tabari, M. J. Nazemosadat, and Z. Maryanaji, 2011: ENSO teleconnection impacts on reference evapotranspiration variability in some warm climates of Iran. Int. J. Climatol., 31, 1710-1723, doi:10.1002/joc. 2187.

—_, R. Mousavi, S. Marofi, N. Ebrahimipak, and M. Heidari, 2013: An improved estimation of the Angstrom-Prescott radiation coefficients for the FAO56 Penman-Monteith evapotranspiration method. Water Resour. Manage., 27, 2839-2854, doi:10.1007/s11269-013-0318-z.

Sadrinasab, M., and J. Kämpf, 2004: Three-dimensional flushing times of the Persian Gulf. Geophys. Res. Lett., 31, L24301, doi:10.1029/2004GL020425.

Sale, P., and Coauthors, 2011: The growing need for sustainable ecological management of marine communities of the Persian Gulf. Ambio, 40, 4-17, doi:10.1007/s13280-010-0092-6.

Saleh, D., 2010: Stream gage descriptions and streamflow statistics for sites in the Tigris River and Euphrates River basins, Iraq. U.S. Geological Survey Data Series 540, 146 pp.
Sheppard, C., and Coauthors, 2010: The Gulf: A young sea in decline. Mar. Pollut. Bull., 60,13-38, doi:10.1016/j.marpolbul.2009.10.017.

Shirvani, A., S. M. J. Nazemosadat, and E. Kahya, 2014: Analyses of the Persian Gulf sea surface temperature: Prediction and detection of climate change signals. Arabian J. Geosci., 8, 2121-2130, doi:10.1007/s12517-014-1278-1.

Smagorinsky, J., 1963: General circulation experiments with the primitive equations. Mon. Wea. Rev., 91, 99-164, doi:10.1175/ 1520-0493(1963)091<0099:GCEWTP>2.3.CO;2.

Sofianos, S. S., W. E. Johns, and S. P. Murray, 2002: Heat and freshwater budgets in the Red Sea from direct observations at Bab el Mandeb. Deep-Sea Res. II, 49, 1323-1340, doi:10.1016/ S0967-0645(01)00164-3.

Thoppil, P. G., and P. J. Hogan, 2010: A modeling study of circulation and eddies in the Persian Gulf. J. Phys. Oceanogr., 40, 2122-2134, doi:10.1175/2010JPO4227.1.

Tian, R., and C. Chen, 2006: Influence of model geometrical fitting and turbulence parameterization on phytoplankton simulation in the Gulf of Maine. Deep-Sea Res. II, 53, 2808-2832, doi:10.1016/j.dsr2.2006.08.006.

Tragou, E., C. Garrett, R. Outerbridge, and C. Gilman, 1999: The heat and freshwater budgets of the Red Sea. J. Phys. Oceanogr., 29, 2504-2522, doi:10.1175/1520-0485(1999)029<2504: THAFBO $>2.0 . \mathrm{CO} ; 2$.

Valcke, S., 2013: The OASIS3 coupler: A European climate modelling community software. Geosci. Model Dev., 6, 373388, doi:10.5194/gmd-6-373-2013.

Weisberg, R. H., and L. Zheng, 2006: Circulation of Tampa Bay driven by buoyancy, tides, and winds, as simulated using a finite volume coastal ocean model. J. Geophys. Res., 111, C01005, doi:10.1029/2005JC003067.

Winter, J. M., J. S. Pal, and E. A. B. Eltahir, 2009: Coupling of integrated biosphere simulator to regional climate model version 3. J. Climate, 22, 2743-2757, doi:10.1175/2008JCLI2541.1.

Xue, P., C. Chen, P. Ding, R. C. Beardsley, H. Lin, J. Ge, and Y. Kong, 2009: Saltwater intrusion into the Changjiang River: A model-guided mechanism study. J. Geophys. Res., 114, C02006, doi:10.1029/2008JC004831.

,,-- R. C. Beardsley, and R. Limeburner, 2011: Observing system simulation experiments with ensemble Kalman filters in Nantucket Sound, Massachusetts. J. Geophys. Res., 116, C01011, doi:10.1029/2010JC006428.

, E. A. B. Eltahir, P. Malanotte-Rizzoli, and J. Wei, 2014: Local feedback mechanisms of the shallow water region around the Maritime Continent. J. Geophys. Res. Oceans, 119, 6933-6951, doi:10.1002/2013JC009700.

Yao, F., and W. E. Johns, 2010a: A HYCOM modeling study of the Persian Gulf: 1. Model configurations and surface circulation. J. Geophys. Res., 115, C11017, doi:10.1029/2009JC005781.

$\longrightarrow$, and $-2010 \mathrm{~b}$ : A HYCOM modeling study of the Persian Gulf: 2. Formation and export of Persian Gulf Water. J. Geophys. Res., 115, C11018, doi:10.1029/2009JC005788.

Zeng, X., M. Zhao, and R. E. Dickinson, 1998: Intercomparison of bulk aerodynamic algorithms for the computation of sea surface fluxes using TOGA COARE and TAO data. J. Climate, 11, 2628-2644, doi:10.1175/1520-0442(1998)011<2628:IOBAAF>2.0.CO;2.

Zhao, L., C. Chen, J. Vallino, C. Hopkinson, R. C. Beardsley, H. Lin, and J. Lerczak, 2010: Wetland-estuarine-shelf interactions in the Plum Island Sound and Merrimack River in the Massachusetts coast. J. Geophys. Res., 115, C10039, doi:10.1029/2009JC006085. 